ISSN: 0213-2060

DOI: http://dx.doi.org/10.14201/shhme2016342757

\title{
¿CULTURA POLÍTICA O CULTURA DE LA POLÍTICA EN LOS DISCURSOS DE LA NOBLEZA? UNA CATEGORÍA DE ANÁLISIS PARA EL ESTUDIO DE LA POLITIZACIÓN DE LA NOBLEZA CASTELLANA EN EL SIGLO XV
}

\author{
Political Culture or the Culture of Politics in the Discours of the Nobility? \\ A Category for Studying the Castilian Nobility Politicization in the Fifteenth \\ Century
}

\author{
Ana Isabel CARRASCO MANCHADO \\ Depto. de Historia Medieval. Facultad de Geografia e Historia. Universidad Complutense de Madrid. C/ Profesor \\ Aranguren, s/n.E-28040 MADRID. C. e.: aicarras@ghis.ucm.es
}

Recibido: 2016-06-03

Revisado: 2016-10-10

Aceptado: 2016-10-14

RESUMEN: Este trabajo se plantea qué tipo de cultura política adoptó la nobleza castellana del siglo xv. En primer lugar, se analizan críticamente las definiciones de cultura política que manejan los científicos sociales y los historiadores. En segundo lugar, se analizan diversos estudios sobre la cultura política nobiliar en Castilla y los problemas que esta categoría plantea para entender los comportamientos y valores de la nobleza en la Edad Media. En tercer lugar, se propone una forma distinta de entender la cultura política, más bien como cultura de la política, que transmite ideas sobre la responsabilidad gubernativa (como la idea de bien común). La nobleza castellana adoptó este tipo de cultura y el análisis del discurso empleado en el Seguro de Tordesillas del Conde de Haro (1439) muestra el grado de politización de la nobleza castellana.

Palabras clave: Cultura política; Nobleza; Bien común; Corona de Castilla; Siglo xv; Seguro de Tordesillas; Pedro Fernández de Velasco; Conde de Haro. 
ANA ISABEL CARRASCO MANCHADO CATEGORÍA DE ANÁLISIS PARA EL ESTUDIO DE LA POLITIZACIÓN DE LA NOBLEZA...

ABSTRACT: This study aims to analyze what kind of political culture adopted the Castilian nobility of the fifteenth Century. First, will be analyzed the definitions of political culture that manage social scientists and historians. Second, are analyzed several historical studies on political culture and nobility in Castile, and the problems to understand the behaviors and values of the nobility in the Middle Ages. Thirdly, a different definition of political culture is proposed: the category of culture of politics, with ideas about governance and responsibility (idea of the common good). The Castilian nobility adopted this culture, and an analysis of discourse used by nobles on Seguro de Tordesillas (Conde de Haro, 1439) indicates the degree of politicization of the Castilian nobility.

Keywords: Political culture; Nobility; Common Good; Crown of Castile; Fifteenth Century; Seguro de Tordesillas; Pedro Fernández de Velasco; Conde de Haro.

SUMARIO: 0 Introducción. 1 ¿Cultura política o culturas políticas? Definiciones y revisión crítica. 2 Visiones sobre la cultura política nobiliaria en la Castilla bajomedieval. 3 Una propuesta: la nobleza y la "cultura de la política». Un ejempo a partir del Seguro de Tordesillas, del Conde de Haro (1439). 4 Apéndice. 5 Referencias bibliográficas.

\section{$0 \quad$ INTRODUCCIÓN $^{1}$}

A mediados del siglo Xviı circulaba la idea de que «El gobierno del vasallo en su familia es semejanza del que ha de tener el príncipe en los negocios públicos; que la política es administración de lo doméstico comunicada al bien universal» (Lorenzo Ramírez de Prado. Consejo y consejero de príncipes. Madrid, 1617). La política se ejerce antes en la casa, que es modelo para el gobierno universal. El gobierno del señor y el del príncipe serían, en esencia, del mismo tipo, pero a una escala diferente, ambos interconectados, pues los señores no podrían gobernar la república, si no supieran antes administrar bien su casa. Ejemplo de ello y modelo a seguir en la época fue un noble medieval, Ínigo López de Mendoza, marqués de Santillana:

Es cada familia una República; y así para el político gobierno de las mayores, se ensayan en la económica de sus casas los padres de familia; que el buen Governador ha de tener tres prudencias, la personal para governarse en todo tiempo, la doméstica para su familia, la política para la República. Fue gran padre della el Marqués de Santillana, y gran padre de familia (Luisa María de Padilla, Condesa de Aranda. Idea de nobles y sus desempeños en aforismos. Zaragoza, 1644).

1 Este trabajo se enmarca en el proyecto de investigación financiado por el MINECO, HAR201568209-P: Las transformaciones del Estado: Estructuras politicas, agentes sociales y discursos de legitimación en el Reino de Aragón (siglos XIV-XV). Una perspectiva comparada, Universidad de Zaragoza, dirigido por Carlos Laliena, y en el Grupo de Investigación UCM, n. ${ }^{\circ}$ 930369, de la Universidad Complutense de Madrid. La parte del Seguro de Tordesillas surgió como colaboración en el proyecto Scripta manent. Textos, memoria y poder en linajes bajomedievales. MINECO, HAR2012-34756, dirigido por Cristina Jular (CSIC). 
ANA ISABEL CARRASCO MANCHADO

¿CULTURA POLÍTICA O CULTURA DE LA POLÍTICA EN LOS DISCURSOS DE LA NOBLEZA? UNA CATEGORÍA DE ANÁLISIS PARA EL ESTUDIO DE LA POLITIZACIÓN DE LA NOBLEZA...

El gobierno del señorío - de la casa, para Lorenzo Ramírez de Prado y para la condesa de Aranda- sería el laboratorio de aprendizaje para el gobierno del reino, de alguna manera su fundamento: la economía informando la política².

Estos dos testimonios encabezaban un trabajo que, hace ya un tiempo, analizaba el grado de influencia, representación del poder y efectos económicos de algunas grandes casas nobiliarias, mediante el patronazgo y las redes clientelares durante el Antiguo Régimen $^{3}$. Me ha parecido oportuno iniciar con ellos mi reflexión, pues ejemplifican, en una época posterior a los siglos considerados medievales, el empleo de los referentes culturales que adoptó la nobleza, al menos desde el siglo xv, para consolidar su posición de dominio y de gobierno. La alusión al marqués de Santillana, noble medieval, y él mismo también creador de cultura, es de lo más relevante ${ }^{4}$ ya que muchos de esos referentes que posteriormente serán una y otra vez revitalizados, comenzaron a ser asumidos por las casas nobiliarias durante la Baja Edad Media. Santillana aparece aquí como padre de familia y padre de la República, un papel que igualmente desempeñaba el rey. Si gobierno de señorío (la casa, la familia) y del reino eran semejantes, ¿por qué no considerar el reino como una familia?: «El nombre más conveniente a los reyes y el título de que más se deben preciar es el de Padre de la República, como de una grande familia que está a su cargo, y por este nombre y oficio les pertenece el cuidado de proveer de mantenimiento a sus súbditos» ${ }^{5}$.

Estos y otros elementos culturales (ciertas nociones de política, de economía, de la cosa pública, o de Res publica... procedentes de la tradición filosófico greco-latina), que tal vez puedan calificarse, desde cierta perspectiva, como de "cultura política», interesaron a la nobleza a lo largo del siglo Xv, momento en que también estaban impregnando la caracterización del rey y de su gobierno monárquico. Así pues, puede decirse que la nobleza castellana medieval, y la de siglos posteriores, emplearon discursos que remitín a cierta cultura política. ¿O sería mejor decir "cultura de lo político»?

Al hablar de "cultura política», no solo para referirmos a su posible descripción atendiendo a un grupo social o agente de poder, como la nobleza, sino a la hora de utilizar la expresión misma, preferimos mostrar cierta cautela. Desde hace un tiempo ya, tal noción

2 José María Ortiz indica que esta idea estaba presente ya en Platón, aunque finalmente prefirió subordinar la economía a la política. Este sentido inspiró la definición que los ilustrados dieron a la noción de «economía política»: «forma de conocimiento aplicable a la gobernación de un país»: ORTIZ DE ORRUŃO, José María. «Economía política». En Fernández Sebastián, Javier y Fuentes, Juan Francisco (dirs.). Diccionario politico y social del siglo XIX español. Madrid: Alianza, 2002, p. 250.

3 Atienza Hernández, Ignacio. «Pater familias, señor y patrón: oeconómica, clientelismo y patronato en el Antiguo Régimen». En Pastor, Reyna (comp.). Relaciones de poder, de producción y de parentesco en la Edad Media y Moderna. Madrid: Consejo Superior de Investigaciones Científicas, 1990, pp. 411-412.

4 La condesa de Aranda escribió una Vida del Marqués de Santillana (1644), en la que convertía al marqués en espejo de virtudes aristocráticas. Aurora Egido veía en la defensa de Santillana un interés político de clase, se referió al «campo apenas explorado del mesianismo regresivo que la Edad Media podía suponer en el Barroco»: Egrido, Aurora. "La Nobleza virtuosa de la Condesa de Aranda, dońa Luisa de Padilla, amiga de Gracián». Archivo de Filología Aragonesa, 1998, vol. LIV-LV, p. 41.

5 Valencia, Pedro de. Discurso sobre el precio del pan (1605). En González Cañal, Rafael (ed.). Obras completas. León: Servicio de Publicaciones de la Universidad de León, 1994, vol. IV, p. 31. 

CATEGORÍA DE ANÁLISIS PARA EL ESTUDIO DE LA POLITIZACIÓN DE LA NOBLEZA...

ha ido incorporándose al análisis histórico ${ }^{6}$, y es cada vez más frecuente encontrársela en los trabajos de los medievalistas ${ }^{7}$. En España, su utilización es relativamente reciente ${ }^{8}$, pero en los últimos años ha sido objeto de interés en varios trabajos colectivos, introduciendo así un factor nuevo en el ámbito de la historia política ${ }^{9}$. Sin embargo, a pesar de todo ello, a nuestro juicio, no se ha llegado a establecer un consenso sobre qué sentido debe darse a la "cultura política» desde la historia, de ahí que su utilidad como categoría analítica pueda resultar frágil. Las investigaciones han tratado de adaptar un concepto que parece relativamente novedoso para los historiadores (al menos para los medievalistas),

6 Quizá la primera iniciativa histórica relevante que comenzó a difundir la noción de «cultura política» fue la que giró en torno a los orígenes ideológicos de la Revolución francesa, a finales de los años 80' del siglo xx: Baker, Keith Michael (ed.). The French Revolution and the Creation of Modern Political Culture. Oxford-New York: Pergamon Press, 1987-1989; BAKer, Keith Michael. Inventing the French Revolution: Essays on French Political Culture in the Eighteenth Century. Cambridge: Cambridge University Press, 1990.

A partir de los años 90' del siglo xx y ya a comienzos del siglo xxI, en especial en la historiografía anglosajona, aunque no solo en ella: Hollister, C. Warren (dir.). Anglo-norman political culture and the twelfth-century renaissance. Woodbridge: Boydell Press, 1997; Hicks, Michael. English political culture in the fifteenth century. London-New York: Routledge, 2002; Clarck, Linda y Carpenter, Christine (dirs.). Political Culture in later Medieval England. Woodbridge: Boydell Press, 2004; Walker, Simon. Political Culture in later Medieval England. Manchester: Manchester University Press, 2006; Collard, Franck. Pouvoirs et culture politique dans la France médiévale, V'-XV siècle. Paris: Hachette, 1999; KozIoL, Geoffrey. "Political Culture». En Bull, Marcus (ed.). France in the Central Middle Ages, 900-1200. The Short Oxford History of France. Oxford: Oxford University Press, 2002, pp. 43-76; Vanlandingham, Marta. Transforming the State: King, Court and political culture in the Realms of Aragon (1213-1387). Leiden: Brill, 2002.

8 Uno de los primeros trabajos en los que se abordaba la cuestión versaba sobre la nobleza: QUINTANilla Raso, María Concepción. «Principios y estrategias de la cultura política nobiliaria, redes de solidaridad, clientelismo y facciones en la Córdoba de fines del medievo». En Córdoba, el Gran Capitán y su época. Córdoba: Real Academia de Córdoba de Ciencias, Bellas Letras y Nobles Artes, 2003, pp. 47-74. Al poco tiempo se publicaba el colectivo de Alfonso Antón, M. ${ }^{a}$ Isabel; Escalona Monge, Julio y Martin, Georges (coords.). Lucha politica: condena y legitimación en la España medieval. Lyon: Ens Éditions, 2004. En la Introducción a este volumen, Isabel Alfonso agrupaba bajo la fórmula de «cultura política propia» tres trabajos (de José María Monsalvo, de José Antonio Jara, y de José Ramón Díaz de Durana y Jon Andoni Fernández de Larrea) que estudiaban los conflictos de poder partiendo del análisis del discurso pechero o de la voz del común como recurso legitimador de sus modos de lucha (p. 17). El trabajo de Díaz de Durana y Fernández de Larrea analizaba también el discurso de los parientes mayores, cabezas de la nobleza vasca. El de José María Monsalvo Antón, "Aspectos de las culturas políticas de los caballeros y los pecheros en Salamanca y Ciudad Rodrigo a mediados del siglo xv: violencias rurales y debates sobre el poder en los concejos», pp. 237-296, es el que más expresamente afirmaba la problemática de la cultura política.

9 Foronda, François y Carrasco Manchado, Ana Isabel (dirs.). Du contrat d'alliance au contrat politique. Cultures et sociétés politiques dans la péninsule Ibérique à la fin du Moyen Âge. Toulouse: CNRS-Université de Toulouse-Le Mirail, 2007; Foronda, François y CARrasco Manchado, Ana Isabel (dirs.). El contrato politico en la Corona de Castilla: cultura y sociedad politicas entre los siglos X al XVI. Madrid: Dykinson, 2008; Boucheron, Patrick y Ruiz Gómez, Francisco (coords.). Modelos culturales y normas sociales al final de la Edad Media. Cuenca: Universidad de Castilla-La Mancha y Casa de Velázquez, 2009, con una sección sobre cultura política de las monarquías. Monsalvo Antón, José María (ed.). Sociedades urbanas y culturas políticas en la Baja Edad Media castellana. Salamanca: Ediciones Universidad de Salamanca, 2013 y el volumen monográfico complementario "Culturas políticas urbanas en la Península Ibérica». Edad Media. Revista de Historia, 2013, n. ${ }^{\circ}$ 14. Nieto Soria, José Manuel y Villarroel González, Óscar (coords.). Pacto y consenso en la cultura politica peninsular, siglos XI al XV. Madrid: Sílex, 2013. Otro monográfico reciente, "Ciudad y cultura política urbana en la Edad Media», que recoje las Actas del III Congreso Internacional de Jóvenes Medievalistas Ciudad de Cáceres, en Roda da Fortuna. Revista Eletrônica sobre Antiguidade e Medievo, 2015, vol. 1-1. 
pero que tiene ya una larga trayectoria, desde que los estudiosos de la ciencia política americana comenzaran a difundirlo a mediados del siglo xx. Politólogos, sociólogos, antropólogos -y ahora también historiadores- han ido ensanchando el marco de su definición hasta convertirlo casi en un cajón conceptual ${ }^{10}$. Ello nos ha hecho preguntarnos sobre los límites de su utilización en el marco de la historia medieval, y nos ha incitado, además, a tratar de encontrar una aproximación distinta a la habitual, eludiendo la simple aplicación de un concepto contemporáneo.

En el presente trabajo realizaremos una aproximación metodológica a la noción de "cultura política» y a sus posibles expresiones en los discursos de la nobleza castellana bajomedieval. En este objetivo estamos aunando dos problemas: el de la consideración de la categoría de análisis "cultura política" y el de su validez para caracterizar los valores o comportamientos de la nobleza. La aproximación que planteamos es metodológica, porque, en primer lugar, pensamos necesario clarificar cuál es el sentido de cultura política que resulta más útil para la historia. El sentido que se dé a esta noción condiciona el análisis, y más cuando unas veces se considera en singular y otras veces en plural. Es preciso clarificar esto, antes de abordar la posible diversidad de culturas políticas actuando en el mismo sistema cultural medieval, esto es, la presencia de subculturas, como la nobiliar. Para ello, hemos considerado necesario hacer un repaso historiográfico y detenernos en las diferentes definiciones que se han utilizado en los estudios. Una vez revisada esta problemática, podremos abordar la segunda pregunta que planteamos, que tiene que ver, pues, con la hipótesis de si la nobleza desarrolla una cultura política propia, o subcultura, cuestión que ya ha sido planteada para otros grupos o segmentos sociales en la Edad Media. En la historiografía reciente castellana se ha afirmado la existencia de culturas políticas propias de los pecheros ${ }^{11}$, o de un sector reducido de este grupo, la élite pechera ${ }^{12}$, o entendido también en su delimitación más amplia, como "cultura política popular»o «del común»"

10 Una de las críticas al concepto viene referida por la ambigüedad y por la multiplicidad de definiciones: Bobes, Velia Cecilia. "Cultura política». En Léxico de la política. México: Flacso México, SEP-Conacyt, FCE, Heinrich Böl, 2000, p. 127.

11 Además del artículo ya mencionado de Monsalvo Antón, «Aspectos de las culturas políticas de los caballeros y los pecheros», del mismo autor, "Ideario sociopolítico y valores estamentales de los pecheros abulenses y salmantinos (ss. XIII-Xv)». Hispania, 2011, vol. LXXI, n. ${ }^{2}$ 238, pp. 325-362.

12 Lo afirmaba Mondragón, Silvina Andrea. «Participación política de pecheros en Castilla tardomedieval: los posibles márgenes de acción entre la diferenciación socioeconómica del sector y la imposición del concejo cerrado". Espacio, Tiempo y Forma. Serie III, Historia Medieval, 2012, vol. 25, pp. 309-326; y lo ha desarrollado en «Participación política de pecheros mirobrigenses en el feudalismo tardío: del usufructo de la retórica formal del discurso a la vertebración de una cultura política propia». En la España Medieval, 2014, vol. 37, pp. 277-294.

13 H. Rafael Oliva dice expresamente dedicarse al estudio de la "cultura política popular» en OLIVA Herrer, Hipólito Rafael. “La prisión del rey”: voces subalternas e indicios de la existencia de una identidad política en la Castilla del siglo Xv». Hispania, 2011, vol. LXXI, n. ${ }^{2}$ 238, p. 367. En los trabajos de Oliva Herrer, el problema de definición se complica al introducir la equivalencia con la noción de «identidad». Por su parte, Jesús Á. Solórzano, en una perspectiva similar a la de José María Monsalvo, afirma una «cultura política del común» diferente a la de los linajes de regidores en las ciudades cantábricas: Solórzano TelEchEA, Jesús Ángel. «Commo uno más del pueblo: acción colectiva y ambiciones políticas del común en las villas portuarias de Cantabria en la Baja Edad Media». Edad Media. Revista de Historia, 2013, vol. 14, p. 251. 
ANA ISABEL CARRASCO MANCHADO

¿CULTURA POLÍTICA O CULTURA DE LA POLÍTICA EN LOS DISCURSOS DE LA NOBLEZA? UNA CATEGORÍA DE ANÁLISIS PARA EL ESTUDIO DE LA POLITIZACIÓN DE LA NOBLEZA...

campesina ${ }^{14} ; \mathrm{y}$ también de los caballeros regidores ${ }^{15}$ o de los linajes banderizos ${ }^{16}$. Para el caso de la alta nobleza, ya hemos indicado que las contribuciones sobre este sector fueron de las primeras en plantear la cuestión ${ }^{17}$.

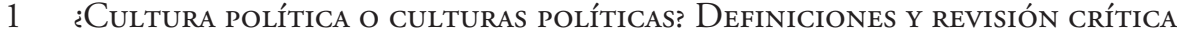

Los historiadores que se han ocupado de la cultura política han tomado, de forma más o menos ajustada, los componentes de la definición que los politólogos americanos Gabriel Almond y Sidney Verba, entre otros, emplearon en sus estudios; una definición que incluía conocimientos, valores, normas, actitudes y sentimientos de la población que orientaban la acción política en los diferentes sistemas políticos, y que eran conformados por el proceso de socialización ${ }^{18}$. No obstante, aun manteniendo algunos de estos componentes, las modificaciones introducidas por los historiadores han sido relevantes.

14 Anteriormente también H. Rafael Oliva se ocupó de la defensa de una «cultura política campesina»o «cultura política en el mundo rural»: Oliva Herrer, Hipólito Rafael. y Challet, Vincent. «La sociedad política y el mundo rural a fines de la Edad Media». Edad Media. Revista de Historia, 2005-2006, vol. 7, pp. 75-98.

15 Nuevamente, los trabajos de Monsalvo citados, en los que contrapone cultura política pechera y de caballeros regidores, más Monsalvo Antón, José María. «Torres, tierras, linajes, mentalidad social de los caballeros urbanos y de la élite dirigente en la Salamanca medieval (siglos XIII-Xv)». En Monsalvo Antón, Sociedades urbanas y culturas políticas, pp. 165-230.

16 Díaz de Durana Ortiz de Urbina, José Ramón y Fernández de Larrea y Rojas, Jon Andoni. "Acceso al poder y discurso político en las villas cantábricas al final de la Edad Media». Edad Media. Revista de Historia, 2013, vol. 14, pp. 63-80.

17 Además del citado anteriormente, los trabajos de Quintanilla Raso, María Concepción. «Fórmulas y prácticas de la cultura política nobiliaria: los grandes en la crisis dinástica castellana (1498-1507)». En Nieto Soria, José Manuel y López Cordón, María Victoria (eds.). Gobernar en tiempos de crisis. Las quiebras dinásticas en el ámbito hispánico (1250-1808). Madrid: Sílex, 2008, pp. 199-220; "Consenso, pacto, amistad y seguridad. Escrituras y tácticas nobiliarias en la Castilla del siglo XV». En Nieto Soria y Villarroel González (coords.), Pacto y consenso, pp. 65-91. Con anterioridad, reflexionó sobre la cuestión Carrasco Martínez, Adolfo. «La nobleza e Isabel I. La evolución de los grandes linajes castellanos y la formación de la cultura política nobiliaria a fines del siglo xv». En Los Reyes Católicos y Granada. Granada: SECC, 2004, pp. 59-68; aquí retoma planteamientos más ampliamente desarrollados en «La consolidación del poder de la alta nobleza castellana y la formación de la conciencia nobiliaria en tiempos de crisis, 1490 y 1530 ». En BELENguer Cebrià, Ernest (coord.). De la unión de coronas al Imperio de Carlos V. Madrid: SECC, 2001, vol. 1, pp. 183-210. Para siglos posteriores, sus trabajos «Los Grandes, el poder y la cultura política de la nobleza en el reinado de Carlos II». Studia Historica. Historia Moderna, 1999, vol. 20, pp. 77-136 y «Cultura política e identidad aristocráticas en la Europa de los reyes y los privados». Cuadernos de Historia de España, 2001-2002, vol. 77, pp. 165-186.

18 Almond, Gabriel A. y Verba, Sidney. The Civic Culture: Political Attitudes and Democracy in Five Nations. Princeton: Princeton University Press, 1963. Sus análisis tienen que ver con la teoría de la modernización y han sido fuertemente contestados, pues partían del sistema político occidental como el ideal. Se trataba de ver qué culturas políticas contribuían a retrasar o a acelerar la adopción del sistema democrático. Se hablaba de una evolución de culturas políticas en Occidente: las tradicionales (cultura política parroquial, del súbdito, de participación, parroquial de súbdito, del súbdito participante y parroquial participante), una cultura mixta entre la tradicional y moderna, que era la cultura cívica, y la cultura política moderna. El primer capítulo de esta obra, "An Approach to Political Culture». En Batlle i Rubio, Albert. Diez textos básicos de ciencia politica. Barcelona: Ariel, 1992, pp. 171-201. 
ANA ISABEL CARRASCO MANCHADO

¿CULTURA POLÍTICA O CULTURA DE LA POLÍTICA EN LOS DISCURSOS DE LA NOBLEZA? UNA CATEGORÍA DE ANÁLISIS PARA EL ESTUDIO DE LA POLITIZACIÓN DE LA NOBLEZA...

Michael Keith Baker, coincidiendo con los postulados del llamado "giro lingüístico", introducía un nuevo componente, el discursivo. Frente a la cultura política del Antiguo Régimen, afirmaba la aparición de una nueva cultura política con la Revolución francesa, basada en la contestación, ya que, para este historiador, «hacer política» es "hacer reclamaciones", formular o expresar demandas, y para ello entraron en juego diferentes prácticas discursivas y también simbólicas que terminaron constituyendo esa nueva cultura política ${ }^{19}$. Entre los aspectos de esa cultura política nueva estaría la opinión pública, cada vez más tenida en cuenta como criterio de autoridad para sostener la oposición al poder monárquico, a pesar de ser una invención reciente, a juicio de Baker ${ }^{20}$. En la época pre-revolucionaria, en el Antiguo Régimen, la cultura política no se expresaría mediante una opinión pública autorizada. Hay que advertir que la evolución histórica marcada aquí, según la cual opinión pública y discursos de reclamación son rasgos de la cultura política postrevolucionaria, no se adecua con las propuestas de los estudios sobre la Edad Media, para los cuales la propaganda y la opinión pública son aspectos relevantes. Pero volveremos de inmediato sobre esta cuestión.

Antes quiero referirme a otra definición de cultura política ampliada, propuesta también por otro historiador, Serge Berstein. Aunque sus investigaciones se orienten hacia el siglo xx, su revisión crítica del concepto permite observar cómo ha sido entendida esta noción por los historiadores ${ }^{21}$. Se preguntaba en un trabajo teórico si este concepto seguía siendo útil para el historiador, dada la complejidad de una categoría que no cabe separar del sistema cultural global de la sociedad, y dada la propia indeterminación de la noción de «cultura». En principio, cultura política sería el conjunto de comportamientos colectivos, sistemas de representación y valores de una sociedad dada aplicados al campo de lo político. Concretando un poco más, se nos define como:

La culture politique telle qu'elle apparaît à l'historien est un système de represéntations fondé sur une certaine vision du monde, sur une lecture signifiante, sinon exacte, du passé historique, sur le choix d'un système institutionnel et d'une société idéale, conformes aux modèles retenus, et qui s'exprime par un discours codé, des symboles, des rites qui l'évoquent sans qu'une autre médiation soit nécessaire. Mais ce système est porteur de normes et de valeurs positives pour celui qui adhère à cette culture, et constitue ainsi l'aune à laquelle il mesure la validité de toute action et de toute position politique ${ }^{22}$.

Como vemos, en su definición se incluyen símbolos y ritos, además de discursos. Todo el sistema cultural parece estar integrado en la cultura política. Para este historiador, consciente de las dificultades, el concepto resulta útil solo si es posible identificar diferentes familias de culturas políticas, y su relación con la cultura política dominante. Sirve, a su juicio, para dar respuesta al problema de las motivaciones políticas y como factor

19 BAKer, Keith Michael. «El concepto de cultura política en la reciente historiografía sobre la Revolución francesa». Ayer, 2006, vol. 64, n.o 2, pp. 89-110, definición en p. 94.

20 BAKER, «El concepto de cultura política», p. 99.

21 Berstein, Serge (dir.). Les cultures politiques en France. Paris: Le Seuil, 1999.

22 Berstein, Serge. "L'historien et la culture politique». Vingtième Siècle. Revue d'Histoire, 1992, vol. 35, pp. 67-77. 
ANA ISABEL CARRASCO MANCHADO

¿CULTURA POlÍ́TICA O CULTURA DE LA POLÍTICA EN LOS DISCURSOS DE LA NOBLEZA? UNA CATEGORÍA DE ANÁLISIS PARA EL ESTUDIO DE LA POLITIZACIÓN DE LA NOBLEZA...

de identificación de los grupos. Ahora bien, notemos que estas familias no se definen en función de los grupos o clases sociales, sino por unos componentes culturales que pueden distinguirse unos de otros. De este modo, para el siglo xx, Berstein identificaba como familias de culturas políticas la republicana, la liberal, la marxista, o socialista, la demócrata-cristiana, la contra-revolucionaria, la tradicionalista... Los grupos o individuos se adhieren o son socializados en unas u otras. Como puede observarse, en este análisis, la cultura política parece identificarse con la noción de ideología.

A la luz de estos planteamientos, ¿qué puede decirse de la cultura política en la Edad Media, o en épocas anteriores a la Modernidad? La complicación se acrecienta, desde luego, ante la dificultad de delimitar ideologías para los grupos de la Edad Media, aunque no falten estudios que lo han intentado. Aún así, no se ha desdeńado su utilidad, tal y como defiende Xabier Gil Pujol, que prefiere hacer uso del plural (culturas políticas), también para los siglos de la Edad Moderna, momento en el que, a su juicio, pueden observarse diferentes concepciones sobre la forma de organizar la sociedad políticamente, pero teniendo en cuenta, claro está, los límites de lo que era "políticamente pensable» en la época y cómo se expresaba: el buen gobierno, el bien común, el respeto al pasado y al orden social que se derivaba de ello. Como forma de análisis de los valores que subyacen en las acciones políticas se nos propone de manera prioritaria el lenguaje ${ }^{23}$. Y esta idea es igualmente planteada por Jan Dumolyn, que ha repasado el uso que hacen de la noción ciertos historiadores, reconociendo la vaguedad constatada por algunos de ellos ${ }^{24}$. Aún así, a su juicio, la cultura política, para resultar un concepto apropiado en el estudio de la Edad Media, debe entenderse, fundamentalmente, como comunicación (intensamente conectada con la propaganda y la opinión pública), esto es, discursos y prácticas relativas a la vida política, no solo circulantes «de arriba a abajo», sino también, «de abajo a arriba». Llegamos así a una concepción muy similar a la que defendió Baker para la nueva cultura política que surge con la Revolución francesa, pues también se trata de una cultura de la reclamación, de la reivindicación y de la protesta. Aquí surge el problema de la falta de adecuación en la evolución histórica observada en los estudios, pues, si ya antes del siglo XviII, en la Edad Media, puede rastrearse tal modalidad de cultura política, ¿cómo entender la evolución histórica y los cambios de modelos experimentados antes y después del Antiguo Régimen sugeridos por Baker ${ }^{25}$ ? ¿Cómo integrar, además, en esa evolución histórica, las diferentes "culturas políticas» o subculturas políticas medievales, entre las que se encontraría la cultura política nobiliar?

23 Gil Pujol, Xabier. Tiempo de politica: perspectivas historiográficas sobre la Europa Moderna. Barcelona: Universitat de Barcelona, 2006, pp. 110 y 167. Son expresión de diferentes culturas políticas las que distinguen a los ingleses de las colonias americanas, que implantaron asambleas representativas, de los de la metrópoli, p. 122.

24 Dedica un apartado a la cultura política Dumolyn, Jan. "Political communication and political power in the Middle Ages: a conceptual journey». Edad Media. Revista de Historia, 2012, vol. 13, pp. 4548. Advierte de la indefinición que sobrevuela en los trabajos de Koziol, Carpenter o Walker (véase nota 7) y recoge la fuerte crítica de G. Gendzel, para quien la cultura política es un "clumpish concept", o de R. P. Formisano, que piensa que es "an umbrella concept», deliberadamente vago (p. 47).

25 Dumolyn, en su repaso historiográfico, no menciona los trabajos de Baker, aunque sí los de Almond y Verba; Dumolyn, «Political communication», p. 46. 
ANA ISABEL CARRASCO MANCHADO

¿CULTURA POLÍTICA O CULTURA DE LA POLÍTICA EN LOS DISCURSOS DE LA NOBLEZA? UNA CATEGORÍA DE ANÁLISIS PARA EL ESTUDIO DE LA POLITIZACIÓN DE LA NOBLEZA...

Los estudios históricos que hemos repasado, con sus definiciones, no ofrecen, quizá, una dirección coherente que permita comprender el fenómeno en su vertiente histórica. Cabe reflexionar un momento ante la razón del uso creciente de una categoría que, como hemos visto, en cualquier caso no parece satisfacer del todo, por su ambigüedad. La noción de cultura política (junto con la de identidad), parece estar sustituyendo a otras categorías tales como mentalidad o ideología, cada vez más en desuso en el discurso histórico, sin que se aprecie una ventaja añadida que supere las deficiencias advertidas en tales categorías ${ }^{26}$. Además, ha englobado en sí aspectos más amplios, del sistema cultural general, que no necesariamente se encierran en algo que se supone tiene que estar bien delimitado (como la cultura política) y que han sido estudiados como objetos en sí mismos, tales como el discurso político, la simbología, el ceremonial, o todo aquello que se ha calificado en alguna ocasión como «la política como representación ${ }^{27}$. Engloba, además, como veremos, todo tipo de comportamientos o prácticas sociales que tienen que ver con el desenvolvimiento de la propia acción política ${ }^{28}$. Este proceso de ampliación de la definición resulta así una vuelta de tuerca más del giro culturalista que ha experimentado la historia en general, desde el último tercio del siglo xx, y la historia política en particular, hasta devenir en una historia cultural de la política. Pero, todo estudio histórico que contemple la relación entre cultura y política, o entre cultura y poder (que no es lo mismo), no debe llevarnos a la conclusión extrema de que «política y cultura se han hecho interdependientes y a la primera se la viene a considerar como una manifestación de la segunda ${ }^{29}$, pues estaríamos entonces renunciando a profundizar en los análisis sociales, los análisis sobre relaciones sociales, entre las que se encuentran las relaciones de dominio, las relaciones de poder; estaríamos, en suma, relegando la historia social de la política ${ }^{30}$.

En las ciencias sociales se han distinguido dos enfoques diferentes que abordan la cultura política desde posiciones divergentes: el politológico y el socio-antropológico. El primero es el que más enfatiza la preferencia de los grupos por unos valores y actitudes para orientar sus comportamientos, y, sobre todo, el que concede un papel a la cultura determinante de la acción, siguiendo la estela clásica weberiana. De este modo, toda

26 El auge y declive de las nociones de mentalidad e ideología, y la evolución hacia planteamientos culturalistas puede verse en Ríos SALOMA, Martín Federico. «De la historia de las mentalidades a la historia cultural. Notas sobre el desarrollo de la historiografía en la segunda mitad del siglo xx». Estudios de Historia Moderna y Contemporánea de México, 2009, vol. 37, pp. 97-137.

27 Nieto Soria, José Manuel. «Sobre la transformación de la historia política en el medievalismo español (ca. 1980-2010)». Cuadernos de Historia de España, 2011-2012, vol. 85-86, p. 517, valora estos aspectos y otros (usos cortesanos, terminología, argumentaciones ideológicas), pero no menciona todavía la cultura política como objeto de preocupación de los medievalistas españoles.

28 John Watts, refiriéndose al contenido que suelen dar los historiadores a lo que denominan «cultura política», incluye también las redes sociales: «ideology (and language), media and social network», pero él la estudia más bien en su sentido intelectual; WatTs, John. The making of polities: Europe, 1300-1500. Cambridge: Cambridge University Press, 2009, p. 130.

29 Gil Pujol, Tiempo de política, p. 405.

30 Véase la crítica de la propuesta de Baker que realiza SEwell, William Hamilton. «Por una reformulación de lo social». Ayer, 2006, vol. 62, pp. 52 y ss. 
ANA ISABEL CARRASCO MANCHADO

¿CULTURA POLÍ́TICA O CULTURA DE LA POLÍTICA EN LOS DISCURSOS DE LA NOBLEZA? UNA CATEGORÍA DE ANÁLISIS PARA EL ESTUDIO DE LA POLITIZACIÓN DE LA NOBLEZA...

acción política termina explicándose por la cultura ${ }^{31}$. El enfoque antropológico, en cambio, ha sometido a crítica mucho más fuertemente la noción de cultura, y, en consecuencia, también la noción de cultura política. La cultura no se entiende como algo homogéneo y estable, sino como heterogéneo y dinámico, como una red de significaciones variables, continuamente construyéndose y en competencia ${ }^{32}$. Y, lo que nos parece más interesante para nuestra reflexión, la cultura no debe confundirse con el comportamiento ni con la acción (tendencia en la que fácilmente podemos caer los historiadores); no comprende el conjunto de relaciones sociales o de poder. Así lo ha expuesto el antropólogo Roberto Varela, que ha diseccionado con acierto la definición de cultura política empleada en numerosos estudios (a partir de la disección previa de las nociones de cultura, de política y de poder). Así, por ejemplo, en muchos estudios la cuestión de la participación política se ha estudiado como un aspecto de la cultura política, y esto es, a juicio de Varela, un error, porque el problema de la participación política corresponde a la propia estructura de poder, no al sistema cultural ${ }^{33}$. Resulta arriesgado incluir la participación política en la cultura porque entonces el problema de una mayor o menor participación dependería de la cultura de los grupos y no sería achacable a las luchas de poder. La cultura debe definirse en términos de signos y símbolos, no de comportamientos, y así, cultura política, podría definirse como ${ }^{34}$ :

Conjunto de signos y símbolos compartidos (transmiten conocimientos e información, portan valoraciones, suscitan sentimientos y emociones, expresan ilusiones y utopías) que afectan y dan significado a las estructuras de poder.

«Dan significado" a las estructuras de poder, no se confunden con ellas; $\mathrm{y}$ "compartidos» no de una manera inmutable, sino dinámica, formando parte de percepciones diversas que pugnan por hacer valer sus diferentes significaciones ${ }^{35}$.

Resumiendo lo dicho hasta aquí, y como conclusión de este apartado, puede decirse que, dentro de la vaguedad de la noción de cultura política, constatada por numerosos estudiosos, es posible delimitar diferentes aproximaciones ${ }^{36}$. En primer lugar, en el sentido politológico clásico, la perspectiva que se ocupa de los valores, sentimientos, comportamientos, actitudes que determinan el comportamiento político. No parece la

31 Schneider, Cecilia y Avenburg, Karen. «Cultura política: un concepto atravesado por dos enfoques». POSTData [online], 2015, vol. 20, n. ${ }^{\circ}$ 1, pp. 109-131. [citado 2016-05-21]. Disponible en: <http:// www.scielo.org.ar/scielo.php?script=sci_arttext\&pid=S1851-96012015000100005\&lng=es\&nrm=iso>

32 Schneider y Avenburg, "Cultura política», pp. 125-126.

33 VARELA, Roberto. Cultura y poder: una visión antropológica para el análisis de la cultura politica. Barcelona-México: Anthropos, Universidad Autónoma Mexicana, 2005, pp. 41 y ss., y p. 148.

34 VArela, Cultura y poder, p. 166.

35 Schneider y Avenburg, "Cultura política», p. 127.

36 Hemos dejado a un lado la perspectiva que relaciona cultura política e identidad territorial o conciencia nacional, ya sea como «culturas políticas provinciales» (GIL Pujol, Tiempo de política, p. 181), de reinos (Ostolaza Elizondo, María Isabel. «Sociedad y cultura política. Nación, bando, familia». En Floristán, Alfredo (coord.). 1512. Conquista e incorporación de Navarra. Barcelona: Ariel, 2012, pp. 335-359), dentro de la Monarquía hispánica. Casi como sinónimo de cultura política occidental, ReInHard, Wolfgang. "Qu’est-ce que la culture politique européenne?». Monográfico Culture politique et communication symbolique. Trivium [En ligne], 2008, vol. 2. Mis en ligne le, 23 octobre 2008, consulté le 24 mai 2016. http://trivium.revues.org/902. 
fórmula más adecuada al análisis histórico, si no se aclara la relación existente entre los valores y las acciones políticas; esto es, si no se distingue claramente el ámbito de las acciones, de las prácticas, del ámbito de los valores ${ }^{37}$. Tampoco parece adecuado apoyar la capacidad determinante de los valores, ya que la acción, o las prácticas sociales, pueden también determinar la asunción de unos valores u otros.

En segundo lugar, encontramos la perspectiva histórica, según la cual se produce una transformación en la cultura política, al final del Antiguo Régimen y con la Revolución francesa, una cultura basada en prácticas y discursos orientados a formular reclamaciones, cobrando especial importancia la opinión pública como fenómeno novedoso. Esta perspectiva no nos valdría para la Edad Media, ya que implica la irrelevancia del uso de tales fórmulas en la sociedad medieval, lo cual contradice los numerosos estudios existentes sobre comunicación política ${ }^{38}$. Contradice, en especial, todo el universo del agravio, de la petición, de la reclamación considerada de índole política ${ }^{39}$, que se formula en la Edad Media por procedimientos mayoritariamente jurídicos. No es extraño que buena parte de las fuentes que se han utilizado para el estudio de la cultura política en la Edad Media sean, precisamente, procesos judiciales. Minusvalora, además, las formas de protesta, tan extendidas, sobre todo, a lo largo de la Baja Edad Media.

Una tercera perspectiva, la introducida por la crítica antropológica antes mencionada, ofrece una visión más dinámica y más acotada (al menos en principio), ya que se trata de estudiar los discursos, símbolos, ritos, creencias y todo aquello que, como matriz cultural, los grupos manejan para representar o dar significado a las acciones que constituyen la relación de poder. Tales herramientas no determinan la acción, sino que se emplean como instrumentos de la acción. El inconveniente de esta perspectiva es que la multiplicidad de significaciones y de representaciones que pueden acompañar a la acción, según los contextos, termina volviendo innecesaria la consideración de culturas políticas diferenciadas, sobre todo en la Edad Media tardía, que carga con el bagaje del sistema cultural cristiano y del feudalismo, a los que remiten muchas de las valoraciones, símbolos y significaciones, añadiendo, además, otras tradiciones intelectuales, como el humanismo ${ }^{40}$.

37 Precisamente, ejemplo de estudio, en el que valores y acciones se mezclan en la configuración de la cultura política, ya sea el derecho de resistencia, fundado en la práctica jurídica, o la violencia de estado, como la desplegada por Carlos V en las ciudades del Imperio, es el citado de ReinHARD, «Qu'est-ce que la culture politique européenne?».

38 El sistema de comunicación (la forma en que los miembros de las sociedades políticas comunican sus ideas sobre el poder, manifestando su adhesión o rechazo a cómo lo ejerce el rey o el poder soberano) es un aspecto esencial en la concepción de cultura política que sostiene Jean-Philippe Genet. Esta cultura política, para él, es aspecto caracterizador de la génesis del Estado moderno; Genet, Jean Philippe. «Culture et communication politique dans l'État européen de la fin du Moyen Âge». En Berstein, Serge y Milza, Pierre (dirs.). Axes et méthodes de l'histoire politique en France. París: PUF, 1998, pp. 273-290; La Genèse de l'État moderne. Culture et société politique en Angleterre. Paris: PUF, 2003; «Modelos culturales, normas sociales y génesis del Estado moderno». En Boucheron y Ruiz Gómez (coords.), Modelos culturales y normas sociales, pp. 17-38.

39 Sobre este aspecto de la reclamación, véase el proyecto dirigido por BuBENICEK, Michelle (dir.). Doléances. Approches comparées de la plainte politique comme voie de régulation dynamique des rapports gouvernants-gouvernés (fin XIII'-premier XIXe s.). Besançon: Cahiers de la MSHE Ledoux (en prensa).

40 Sobre esta última cuestión, véase GILli, Patrick. Droit, humanisme et culture politique dans l'Italie de la Renaissance. Montpellier: Presses Universitaires de la Méditerranée, 2014. 
ANA ISABEL CARRASCO MANCHADO CATEGORÍA DE ANÁLISIS PARA EL ESTUDIO DE LA POLITIZACIÓN DE LA NOBLEZA...

Si se prefiere adoptar el modelo de las subculturas, según grupos o segmentos sociales, habrá que tener en cuenta que es muy difícil compactar un conjunto homogéneo de significaciones o representaciones atribuibles en exclusiva a un solo grupo. En no pocas ocasiones los grupos adoptan instrumentos discursivos o simbólicos del sistema cultural general, ampliamente compartidos por diferentes sectores. De ahí que resulte casi imposible de aprehender, a nuestro juicio, algo homogéneo y permanente que podamos denominar "cultura política de grupo" en una época como la Edad Media, cuyas significaciones o discursos, por otra parte, solo se nos aparecen en corpus heterogéneos y discontinuos de fuentes. No podemos aplicar a la Edad Media un programa de «encuesta de valores», tal y como se hace en la actualidad. Las motivaciones de la acción necesariamente hay que extraerlas de los textos, de fuentes condicionadas por el contexto de producción, por la transmisión, por las mediaciones, por la finalidad. Podemos emprender, incluso de forma pormenorizada, el análisis del discurso mediante el cual se formulan todo tipo de justificaciones, argumentaciones, peticiones, reclamaciones, protestas, referidas a diferentes contextos de acción en los que se desenvuelven las relaciones de poder, pero más difícil resulta, a nuestro juicio, la atribución de tales discursos, de forma bien delimitada, congruente y contrapuesta, a grupos sociales distintos.

Dicho esto, parecería que no es posible afirmar nada sobre la cultura política de un grupo como el de la nobleza. Sin embargo, ya se ha escrito al respecto. Repasaremos ahora algunos de los planteamientos relativos a la nobleza castellana y a la cultura política de la nobleza para, finalmente, avanzar nuestra propuesta.

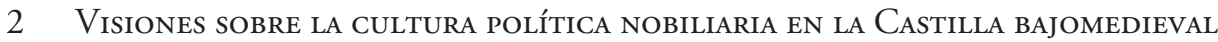

Al hablar de cultura política nobiliaria, o propia de la nobleza, nos referimos a la categoría de análisis tal y como la han venido empleando diversos investigadores de la nobleza en los últimos tiempos, objeto de nuestra reflexión. No nos referimos a la problemática entre cultura y poder nobiliar o señorial ${ }^{41}$, que engloba aspectos sobre mentalidad (incluida la religiosidad, con el patronazgo de instituciones religiosas), valores e ideas relativas a la nobleza (debates sobre la condición noble), sobre el modo de vida (fiestas, rituales, ceremonias...), sobre los mitos y relatos, fundamentos de una particular conciencia de linaje, o sobre la perpetuación de su memoria ${ }^{42}$, o sobre las iniciativas culturales

41 Sobre todos estos temas la bibliografía es amplísima: para la época anterior a 2001, véanse los apartados «Nobleza y cultura medieval. Mecenazgo. Mentalidad e ideología nobiliaria. Modos de vida» de la bibliografía general de Sanz Cuesta, Miriam y Rubio Liniers, María Cruz; García-Hernán, David. La nobleza en España. Madrid: CINDOC, 2001, vol. 1, pp. 189-198. En esta bibliografía, que abarca desde la Edad Media a la Contemporánea, es llamativo que el único trabajo que usa la categoría «cultura politica» sea el de Adolfo Carrasco.

42 Beceiro Pita, Isabel. «La conciencia de los antepasados y la gloria del linaje en la Castilla bajomedieval». En Pastor (comp.), Relaciones de poder, pp. 327-349. Los estudios sobre memoria nobiliar están actualmente muy vigentes: Dacosta, Arsenio; Prieto Lasa, José Ramón y Díaz de Durana, José Ramón (eds.). La conciencia de los antepasados. La construcción de la memoria de la nobleza en la Baja Edad Media. Madrid: Marcial Pons, 2014; además de los trabajos reunidos en Discurso, memoria y representación. La nobleza peninsular en la Baja Edad Media. Pamplona: Gobierno de Navarra, 2016. 
ANA ISABEL CARRASCO MANCHADO

¿CULTURA POLÍTICA O CULTURA DE LA POLÍTICA EN LOS DISCURSOS DE LA NOBLEZA? UNA CATEGORÍA DE ANÁLISIS PARA EL ESTUDIO DE LA POLITIZACIÓN DE LA NOBLEZA...

de la nobleza (mecenazgo, bibliotecas, patrocinio...). Se trata de entender el uso de la categoría "cultura política» (que puede englobar algunos de estos aspectos culturales, pero que incluye más componentes, a juicio de los historiadores que la han empleado, como veremos a continuación) y en qué medida puede ser aplicada para el grupo nobiliar. Vamos a ocuparnos del grupo altonobiliar, aunque la cuestión de la cultura política se ha tratado también para otros niveles aristocráticos ${ }^{43}$.

Como ya hemos indicado, los primeros en utilizar un objeto definido como cultura política fueron Adolfo Carrasco y María Concepción Quintanilla. Analizando el siglo xv, María Concepción Quintanilla se preguntaba en un trabajo de 2003 cuáles eran los principios, criterios y postulados políticos de la alta nobleza castellana en sus relaciones intranobiliares y con la monarquía. Aunque ya había analizado aspectos similares en estudios precedentes, es ahora cuando son agrupados bajo esta categoría ${ }^{44}$. Entre las claves de la cultura política nobiliar menciona la perpetuación de la fórmula del servicio al rey, como mecanismo generador de la gracia regia, bajo expresiones como la de «hechura

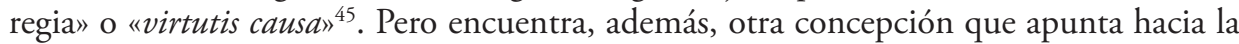
superioridad de la nobleza de sangre, configurando el discurso aristocrático que presenta a los miembros de esta nobleza como una «élite natural» del reino ${ }^{46}$. Este convencimiento marca lo que en su opinión es uno de los puntales de su cultura política: el derecho a intervenir en el sistema de gobierno monárquico y a resistir, incluso, las decisiones del rey, cuando consideren que se estaban lesionando, no solo sus derechos, sino los de las ciudades. Ello les lleva a adoptar, incluso, un principio carismático y providencialista: su actuación en servicio del reino como instrumento divino. Su estudio se centra en los conflictivos ańos del siglo xv, entre 1419 y 1479, período en el que se multiplica la faccionalidad, con especial énfasis en la guerra durante el reinado de Enrique IV, de manera que no se puede obviar la coyuntura. En este contexto, la nobleza apela como postulado de su cultura política al argumento de la «extrema necesidad», que le sirve para legitimar la rebelión contra el rey. Aun así, la nobleza no actuó como un bloque monolítico, sino que se generó una doble posición política según la adhesión a una u otra opción enfrentadas ${ }^{47}$.

En otro trabajo posterior, esta historiadora profundiza en estas ideas y añade, como parte de la cultura política de la nobleza (referida a las grandes casas nobiliarias), las prácticas de acción política y afianzamiento del discurso aristocrático, componentes especialmente ligados a la tensión con los monarcas, que se expresa frecuentemente en una relación de conflicto-pacto ${ }^{48}$. Esa práctica nobiliar consiste en la faccionalidad y

43 Véanse los trabajos citados en las notas 15 y 16.

44 Quintanilla Raso, «Principios y estrategias», pp. 47-74.

45 Quintanilla Raso, «Principios y estrategias», p. 52. Sobre esta cuestión ha profundizado en Quintanilla Raso, María Concepción. «Nobilitas virtutis causa. De la virtud al pecado en la nobleza». En Carrasco Manchado, Ana Isabel y Rábade Obradó, M. a del Pilar (coords.). Pecar en la Edad Media. Madrid: Sílex, 2008, pp. 149-184.

46 Quintanilla Raso, «Principios y estrategias», p. 53.

47 Quintanilla Raso, «Principios y estrategias», p. 56.

48 En un trabajo reciente, incluido en un colectivo sobre cultura política, la autora se refiere a las tácticas para lograr la seguridad como elemento de búsqueda de consenso en las relaciones intranobiliarias: Quintanilla Raso, «Consenso, pacto, amistad y seguridad», pp. 65-91. 
ANA ISABEL CARRASCO MANCHADO CATEGORÍA DE ANÁLISIS PARA EL ESTUDIO DE LA POLITIZACIÓN DE LA NOBLEZA...

en las clientelas, como principales recursos de acción. Pero, de nuevo puntualiza que las diferentes casas no actúan de manera uniforme, sino que siguen posicionamientos particulares vinculados a las opciones regias que se dirimen en los conflictos sucesorios del siglo xv. Los nobles titulados despliegan entonces una suerte de «identidad política», traducida en opciones partidistas, a veces cambiantes, pues la finalidad última es la defensa a ultranza del interés personal (la consecución de "ambiciones», traducidas en términos de patrimonio y poder). También ejecutarían prácticas de acercamiento al monarca y ensalzamiento de las figuras regias, utilizando, por ejemplo, las ceremonias de recepción, los banquetes y fiestas, y todo aquello que suponga la posibilidad de situarse en el entorno regio para lograr canalizar en beneficio propio y de sus linajes los favores y mercedes regias. Los discursos aristocráticos insistirían en la noción de servicio al rey ${ }^{49}$. Así pues, en este trabajo, la autora conjuga prácticas, discursos y rituales, como componentes de la cultura política nobiliar, una cultura que, no obstante, no es homogénea para todo el estamento nobiliar, debido a la competencia entre las casas y linajes, que pugnan por acaparar las mercedes regias. El interés personal alterna también en esta cultura política con el gubernativo, pues, según afirma en otro trabajo, «la tradicional cultura política de la alta nobleza les conducía a intentar buscar su identidad en un sistema basado en el ejercicio plural de la autoridad, la sobernía compartida, o monarquía mixta ${ }^{50}$.

Por su parte, Adolfo Carrasco se refiere a la cultura política de los grandes en el período de los Reyes Católicos ${ }^{51}$, a partir de 1491, hasta 1530 , por lo que es posible ver cómo ha podido evolucionar la cultura política de la nobleza y cómo afrontó la nueva crisis en el reino. Las grandes casas nobles de finales de siglo han consolidado su posición social y económica (con estados señoriales bien organizados y reforzados, gracias a la institución del mayorazgo). Han consolidado también su posición política, ya que han logrado integrarse en las principales instituciones de gobierno de la monarquía a nivel central (consejo real, cancillería). Sin embargo, a comienzos del XVI, a juicio de este investigador, perdieron la posibilidad de articular un discurso sobre el ejercicio de la autoridad y su participación en el gobierno como grupo homogéneo, esto es, no desarrollaron una "conciencia política» sólida ${ }^{52}$. Para este investigador, esta cultura política ineficiente que desarrolla la nobleza se ve especialmente influida por los rasgos propios de la cultura nobiliar, en sentido general («un conjunto de expresiones de un determinado estilo de civilización, y la ética asociada a ésta, el sistema de valores, actitudes y normas de conducta» que configuraron la "conciencia»

49 Quintanilla Raso, «Fórmulas y prácticas», pp. 199-220.

50 Quintanilla Raso, María Concepción. «Discurso aristocrático, resistencia y conflictividad en el siglo xv castellano". En Foronda, François; Genet, Jean-Philippe y Nieto Soria, José Manuel. Coups d'État à la fin du Moyen Âge? Aux fondements du pouvoir politique en Europe occidentale. Madrid: Casa de Velázquez, 2005 , p. 548.

51 Había empleando esta categoría antes en dos trabajos sobre los siglos XVI y XVII, ya citados: CARRAsCo Martínez, «Los Grandes, el poder y la cultura política de la nobleza en el reinado de Carlos II» y "Cultura política e identidad aristocráticas en la Europa de los reyes y los privados».

52 Carrasco Martínez, «La consolidación del poder», p. 202. 
ANA ISABEL CARRASCO MANCHADO

¿CULTURA POLÍtTICA O CULTURA DE LA POLÍTICA EN LOS DISCURSOS DE LA NOBLEZA? UNA CATEGORÍA DE ANÁLISIS PARA EL ESTUDIO DE LA POLITIZACIÓN DE LA NOBLEZA...

nobiliaria) y la cultura del linaje a ella asociada (tal y como fue descrita por Bartolomé Clavero) ${ }^{53}$, centrada en la «sangre esclarecida». La exclusividad de este horizonte mental de la nobleza le imposibilitó desarrollar una visión colectiva. No desarrollaron, tampoco, un "programa de grupo» opuesto al de la monarquía, ya que esta era compatible y necesaria para mantener el sistema de jurisdicción señorial hereditaria que ejercían en sus señoríos. La tensión con la monarquía se resuelve siempre utilizando los pactos y concordias entre los reyes y los linajes particulares. Aquí también cobra especial relevancia la contraposición entre interés particular y general: su participación en el gobierno tiene como finalidad el control de la distribución de las mercedes, de ahí la limitación del programa altonobiliar, obligado, además, a desarrollar una pugna interna ${ }^{54}$. Vemos, pues, que esta rivalidad interna impediría llevar a cabo esa idea de soberanía compartida, o monarquía mixta, que apuntaba Quintanilla como aspiración en la que basar la identidad nobiliar.

A la vista de estas dos perspectivas, en ciertos puntos concurrentes, la conclusión a la que parece llegarse es que la alta nobleza castellana no posee una cultura política propia, si entendemos por esta la asociada a una conciencia política, es decir, una percepción clara y homogénea (de grupo) sobre el papel que debe desempeñar en el gobierno de la Corona. No puede tenerla porque tampoco el grupo es coherente: la división interna entre nobleza de mérito y nobleza de sangre, que los debates intelectuales (encarnados por Diego de Valera y Ferrán Mexía) reflejaban, y la forma de establecer sus relaciones de poder (intranobiliarias y con la monarquía), a través de la competencia de las facciones parentelares-clientelares imposibilitaba la emergencia de lo que estos historiadores buscan cuando se refieren a cultura política. No deja de llamar la atención que en los siglos siguientes, XVI y XVII, buena parte de esta problemática se mantenga, tal y como ha puesto de manifiesto el propio Adolfo Carrasco en otros trabajos sobre esta cuestión. Así por ejemplo, la polémica entre mérito y sangre sigue muy viva en torno a $1600^{55}$, y siguen los grandes tratando de encontrar su lugar en un contexto en el que la gobernanza se asocia con el incremento de poder en manos del monarca absoluto, mostrando una actitud de mayor unidad ante la controvertida acumulación del poder que implica el valimiento, una actitud, por cierto, similar a la que expresaron los grandes medievales en Castilla ante la figura del privado ${ }^{56}$, aunque, de nuevo, no fraguara un programa propiamente aristocrático ${ }^{57}$. Más avanzado el siglo

53 Carrasco Martínez, «La consolidación del poder», pp. 189-192. Se refiere al trabajo de ClaveRO, Bartolomé. «Dictum beati. A proposito della cultura del linaggio». Quaderni Storici, 1994, vol. 86, pp. 335-363.

54 Carrasco Martínez, «La consolidación del poder», pp. 202-210.

55 Carrasco Martínez, «Cultura política e identidad», p. 174.

56 Foronda, François. «La privanza dans la Castille du bas Moyen Âge. Cadres conceptuels et stratégies de légitimation d'un lien de proximité». En Alfonso Antón, Escalona Monge y Martin (dirs.), Lucha politica, pp. 153-197; y «La privanza, entre monarquía y nobleza». En NieTo SoRiA, José Manuel. La monarquía como conflicto en la Corona castellano-leonesa (c. 1230-1504). Madrid: Sílex, 2006, pp. 73-132; así como la síntesis «Privanza». En Martin, Georges (coord.). Diccionario de Historia Medieval Ibérica. Madrid: Akal (en prensa). Agradezco al autor la lectura de este artículo aún no publicado, así como la referencia de la nota 39.

57 Carrasco Martínez, «Cultura política e identidad», p. 185. 
ANA ISABEL CARRASCO MANCHADO

¿CULTURA POLÍTICA O CULTURA DE LA POLÍTICA EN LOS DISCURSOS DE LA NOBLEZA? UNA CATEGORÍA DE ANÁLISIS PARA EL ESTUDIO DE LA POLITIZACIÓN DE LA NOBLEZA...

XVII, en la época de Carlos II, la tratadística al servicio de los grandes sí parece propugnar más claramente la necesaria co-participación de los nobles en el gobierno monárquico, incluso parecen esbozar cierta línea programática de actuación, integrando al valido y a la grandeza ${ }^{58}$. Es como si la cultura política nobiliar hubiera necesitado más de dos siglos para eclosionar.

Expresiones como "conciencia política» o "programa político»" ${ }^{59}$ remiten de alguna manera a un relato clásico de explicación de la crítica situación y de la cadena de conflictos que se vivieron en Castilla desde el triunfo de los Trastámara, al igual que la dinámica de confrontación entre un «interés privado» (encarnado en la nobleza) y un «interés público» (encarnado en la monarquía). Me refiero al relato de Luis Suárez que, aunque impugnado ya como modelo de explicación global ${ }^{60}$, en algunas de sus cuestiones aún sigue suscitando interés, como esta de si la nobleza fue capaz o no de articular un programa de gobierno o de concebir un modelo alternativo al que la monarquía estaba construyendo. Ello supondría la existencia de dos programas de gobierno (o en algunos casos tres ${ }^{61}$, uno nobiliar, otro monárquico, implicado este en un proceso de autoritarismo y de centralización creciente. Todavía, recientemente, Alfonso Franco, en un trabajo sobre los discursos politicos de la nobleza, ha vuelto sobre el análisis de los textos que intervienen en este relato, tales como el Manifiesto de Burgos (1464) o la Sentencia de Medina del Campo (1465), entre otros. La pregunta sigue siendo si "este grupo social logró pensar y formular un modelo de estado radical o parcialmente distinto», si llegó a formular "un razonado programa de gobierno». Su respuesta es positiva, a pesar de los "oscuros intereses de clase», y tal programa de reformas se encarnaría en un modelo de «monarquía nobiliaria» limitadora del poderío real absoluto, que, sin embargo, no prosperó ${ }^{62}$.

Desde una perspectiva diferente, y admitiendo que los nobles adquirieron una responsabilidad gubernativa, el campo de la cultura política se amplía englobando toda una serie de actuaciones. Los estudios de François Foronda sobre la privanza y sobre lo

58 Con críticas más abiertas a la Corona, por parte de los nobles, rasgo de una cultura política nueva según Carrasco Martínez, «Los Grandes, el poder y la cultura política», pp. 119-120.

59 «Programa político» y "cultura política» son sinónimos en el trabajo de SENATORE, Francesco. "La cultura politica di Ferrante d'Aragone». En Gamberini, Andrea y Petralia, Giuseppe (eds.). Linguaggi politici nell'Italia del Rinascimento. Roma: Viella, 2007, pp. 120-133.

60 Suárez Fernández, Luis. Nobleza y monarquía. Puntos de vista sobre la historia politica castellana en el siglo XV. Valladolid: Universidad de Valladolid, 1975 (primera version publicada en 1959; otra versión en Madrid: La Esfera de los Libros, 2003). Sobre la vigencia del modelo y su cuestionamiento por historiadores como José María Monsalvo, Álvarez Borge, Ignacio. «Patrimonio, rentas y poder de la nobleza bajomedieval peninsular». En Discurso memoria y representación, pp. 112-113.

${ }^{61}$ Programa político equivale a "partido». Así, Dolores Morales señalaba el partido aragonés, encabezado por los Infantes de Aragón, y cuyo programa heredará la princesa Isabel; otro grupo llamado «constitucional», defensores de la Sentencia de Medina de 1465, y los partidarios del rey, o partido enriqueño; Morales MuñIz, Dolores Carmen. «Significación e historiografía de Alfonso XII de Castilla. Nuevas vías de investigación». Medievalismo, 1996, vol. 6, pp. 223-224.

62 Franco Silva, Alfonso. Los discursos politicos de la nobleza castellana en el siglo XV. Cádiz: Universidad de Cádiz, 2012, pp. 14-23 y 187-189. 
ANA ISABEL CARRASCO MANCHADO

¿CULTURA POLÍTICA O CULTURA DE LA POLÍTICA EN LOS DISCURSOS DE LA NOBLEZA? UNA CATEGORÍA DE ANÁLISIS PARA EL ESTUDIO DE LA POLITIZACIÓN DE LA NOBLEZA...

que, después de diversas investigaciones ${ }^{63}$, se ha venido en llamar "cultura contractual», conectan así con la cultura política. Se relacionan con ella los contratos de privanza, ciertos rituales, como el del apoderamiento del rey, o, si se quiere, el "golpismo», las diferentes experiencias colectivas contractuales (como los Seguros de Tordesillas, de 1439 y 1451), y (pre)constitucionales (la Sentencia de Medina del Campo, de 1465) y, últimamente, las emociones políticas (el miedo al rey ${ }^{64}$. En todos los discursos, rituales, prácticas que configuran la actuación de la nobleza castellana a lo largo del siglo xv se revelaría una "cultura política propiamente nobiliar»"

\section{UNA PROPUESTA: LA NOBLEZA Y LA "CULTURA DE LA POLÍTICA». UN EJEMPO a partir del Seguro de Tordesillas, del Conde de Haro (1439)}

Después de repasar estas diferentes perspectivas, pensamos que podemos concluir lo siguiente: en primer lugar, que no puede hablarse de una cultura política propia de la nobleza y, en segundo lugar, la escasa utilidad que tiene la categoría "cultura política» para avanzar en la explicación de la lógica social y de poder que se desarrolla al final de la Edad Media en Castilla. Para hablar de una cultura política propia (o subcultura) tendría que estar bien definido el grupo, y, en estos mismos historiadores, se ha revelado la heterogeneidad del grupo nobiliar. Aunque estemos refiriéndonos a la alta nobleza, no se puede obviar el hecho de que esta se organiza mediante una compleja red de solidaridades horizontales y verticales, que integran a grupos de parentesco, de afinidad y de amistad, nobles y no nobles, solidaridades que no necesariamente forman un conjunto coherente ni estable ${ }^{66}$. La agrupación en «linajes» o «casas» (25 en el reinado de los Reyes Católicos) ${ }^{67}$, y la consideración de que la pauta de comportamiento que predomina entre ellos es la competencia por acaparar mercedes regias y beneficios de las rentas reales, redundan en esa falta de coherencia y de cohesión de grupo. A ello hay que ańadir algo no poco importante, que es la implicación del alto clero en las mismas facciones y redes de solidaridad,

63 Además de los trabajos mencionados en nota 9, véase Foronda, François (dir.). Avant le contrat social. Le contrat politique dans l'Occident médiéval XIII'-XVe siècle. Paris: Publications de la Sorbonne, 2011, en concreto la sección presentada por AsEnjo, María. «La cultura pactual hispánica», pp. 437-449.

64 Las «emociones políticas», que, junto con ciertos rituales, que señalan prácticas de poder, formarían parte de la cultura política, p. 77. Foronda, François. El espanto y el miedo. Golpismo, emociones politicas y constitucionalismo en la Edad Media. Madrid: Dykinson, 2013, p. 77.

65 FORONDA, «La privanza, entre monarquía y nobleza», pp. 111 y 119.

66 Sobre la validez teórica y rasgos de las «solidaridades verticales» como categoría de análisis social, véase Díaz de Durana, José Ramón y Dacosta, Arsenio. «La dimensión social del linaje: solidaridad, poder y violencia (País Vasco, siglo Xv)». Studia Zamorensia, 2013, vol. XII, pp. 87-106, esp. 105. El objetivo que cohesiona es el intercambio de bienes y servicios recíprocos.

67 Quintanilla Raso, María Concepción. «El engrandecimiento nobiliario en la Corona de Castilla. Las claves del proceso a finales de la Edad Media». En Quintanilla Raso, María Concepción (dir.). Titulos, grandes del Reino y grandeza en la sociedad politica. Fundamentos en la Castilla medieval. Madrid: Sílex, 2006, pp. 90-100. 

CATEGORÍA DE ANÁLISIS PARA EL ESTUDIO DE LA POLITIZACIÓN DE LA NOBLEZA...

o grupos parentelares, lo cual lleva a poner en duda, para este análisis, la validez del concepto mismo de nobleza, ya que a quien vemos actuar en todos los conflictos es a la aristocracia en su conjunto ${ }^{68}$. Por otro lado, la incompatibilidad apuntada por los investigadores mencionados entre «interés privado» e «interés público» tampoco favorece la asunción de una cultura política propia, ni aun circunscribiendo esta al interés público, ya que, en una sociedad jerarquizada y de privilegio como la medieval, no hay una clara distinción entre lo privado y lo público ${ }^{69}$. Esto no quiere decir que no existan indicios de que cierta concepción de lo público comienza a delinearse en la sociedad, pero no necesariamente se encarna en exclusiva ni en la figura del rey, ni en otro grupo. La noción de «interés» debe ser objeto de análisis histórico, pero con las debidas precauciones metodológicas que eviten la atribución de juicios de intenciones a los actores históricos.

Recordemos la observación de S. Berstein citada en el primer apartado de este estudio: la noción de cultura política solo es útil si se distinguen familias de culturas políticas y si explica las motivaciones de las acciones o funciona como factor de identificación de los grupos. La cultura política de la nobleza, según se ha examinado, para cumplir estas condiciones, debería poder distinguirse u oponerse a otras modalidades de culturas, la primera de las cuales sería la cultura política que define a la monarquía. Si se entiende la cultura política como prácticas ${ }^{70}$, ya sea en términos de faccionalidad o de consenso, es sabido que la propia realeza comparte estas mismas prácticas, integrándose en alguna de las facciones en pugna y estableciendo alianzas, confederaciones, contratos (como los contratos de privanza de Enrique IV con sus «especiales servidores» $)^{71}$, o grandes amistanzas, como la que Juan II intentó promover con el Seguro de Tordesillas. Si tratamos de aislar la cultura política nobiliar en sus discursos y justificaciones, tampoco hay una distinción radical de la realeza en sus motivaciones, puesto que parece claro, según han mostrado diversos estudiosos, que la nobleza no estaba en contra del desarrollo del poderío real absoluto ni de la centralización monárquica,

68 La necesidad de fundamentar semánticamente la terminología de los grupos sociales (con nuevos métodos) sigue siendo una tarea pendiente. La categoría «nobleza» como definición de un grupo social, además de una cualidad, es una construcción tardía en la Edad Media y obedece a una recomposición de la aristocracia en el marco del feudalismo monárquico: sobre este punto, véase el análisis semántico de MorSEL, Joseph. "Quelques propositions pour l'étude de la noblesse européenne à la fin du Moyen Âge». En Discurso, memoria y representación, pp. 449-499.

69 De ahí que estas dos ideas sean solo contradictorias en apariencia: «Es dudoso que la nobleza, incrementando sin freno sus poderes, sus rentas y sus pretensiones, haya actuado con visión o sentido de Estado en aquellos ańos. Más bien parece que se limitaba cada linaje a saciar sus deseos de poder y riqueza», y esta otra «Es bien sabido que en las sociedades feudales hubo siempre una integración mucho más visible y aceptada que, por ejemplo, en las capitalistas, entre riqueza y poder político»; LADERo Quesada, Miguel Ángel. «La consolidación de la nobleza en la Baja Edad Media». En Ladero Quesada, Miguel Ángel. Poder político y sociedad en Castilla. Siglos XIII al XV. Madrid: Dykinson, 2015, pp. 381 y 389.

${ }^{70}$ Algo no recomendable, según hemos visto en el primer apartado de este estudio, ya que se oscurece el análisis social.

71 Foronda, François. «Vers un gouvernement de jure dans la Castille du Xve siècle: les contrats de privanza d'Henri IV de Trastamare». En Foronda y Carrasco Manchado (dirs.), Du contrat d'alliance, pp. 185-244. 
ANA ISABEL CARRASCO MANCHADO

¿CULTURA POLÍTICA O CULTURA DE LA POLÍTICA EN LOS DISCURSOS DE LA NOBLEZA? UNA CATEGORÍA DE ANÁLISIS PARA EL ESTUDIO DE LA POLITIZACIÓN DE LA NOBLEZA...

necesaria para la consolidación y reproducción del orden social señorial ${ }^{72}$. Y, al fin y al cabo, el rey y la familia real son también poderes señoriales y una parte de la aristocracia. Nobleza y realeza contribuyeron a la construcción de la monarquía como sistema de gobierno, proceso del que realeza y nobleza fueron menos conscientes de lo que se suele considerar ${ }^{73}$.

La categoría de "cultura política» podría resultar más operativa si se circunscribe su significado. Quizá la excesiva amplitud de las definiciones teóricas al uso se deba a que no han tenido en cuenta que no basta con acotar el término "cultura», sino que hay que acotar también el de "política», un concepto que, como muchos historiadores han advertido, no existe en la Edad Media, o, al menos, no existe tal y como lo entendemos hoy. La "política» se redescubre en torno al siglo XII, y a partir de entonces la palabra comienza a ser cada vez más frecuentemente empleada. Se forja así un significado medieval del concepto, pero referido, claro está, a las representaciones mentales medievales, lo "políticamente pensable» en la época. Tal significado girará en torno a la idea de buen gobierno y bien común. En el siglo xx es cuando ese significado medieval, que permaneció, con matices, a lo largo del Antiguo Régimen, cambiará de sentido hacia formas equivalentes a poder, dominio, coerción ${ }^{74}$. Así, lo que con mucha frecuencia suele estudiarse como cultura política, es en realidad cultura del poder (del poder señorial, para el caso de la nobleza). Se retrotrae al pasado medieval una concepción de lo político que es en realidad contemporánea. Vale la pena, sin embargo, tratar de estudiar la relación entre cultura y política desde esta perspectiva, esto es, desde el análisis de la asunción por parte de los grupos sociales medievales de esa visión nueva que supone el descubrimiento de lo político. Aquí lo cultural cobra un importante relieve, ya que, al no tener todavía lo político un ámbito de aplicación aislada de otros fenómenos de actuación en la sociedad, es la cultura la que lo vehicula, y su lenguaje asociado, entendiendo aquí cultura en su sentido más concreto, como conjunto de tradiciones intelectuales, ideas y discursos. John Watts ha resaltado que en torno a 1300 se generaliza el sentido de comunidad política y las responsabilidades que lleva consigo $^{75}$, y François Foronda suele referirse al proceso de asunción de la responsabilidad

72 Julio Valdeón afirmó que el fortalecimiento del rey era la condición necesaria para que la nobleza se consolidase, según recordaba Salustiano de Dios, que formuló la noción de "absolutismo necesario» en un trabajo clásico; Dios, Salustiano de. «Sobre la génesis y los caracteres del Estado absolutista en Castilla». Studia Historica. Historia Moderna, 1985, vol. 3, pp. 36-46. Siguiendo esta línea, Nieto Soria escribe sobre la contribución de la nobleza al establecimiento del régimen de "gobierno por la gracia», y niega la oposicion de la nobleza al poderío real absoluto: Nieto Soria, José Manuel. "La nobleza y el "poderío real absoluto" en la Castilla del siglo Xv». En Conceptions politiques de la noblesse. Monográfico de Cahiers de Linguistique et de Civilisation Hispaniques Médiévales, 2002, vol. 25, pp. 249-254.

73 «Si el Estado fue absoluto fue gracias al poder señorial», Dios, «Sobre la génesis», p. 30.

74 Fernández Sebastián, Javier. «Política». En Fernández Sebastián y Fuentes (dirs.), Diccionario político y social del siglo XIX español, pp. 535-552; y, del mismo autor, «Política». En Fernández SEBASTIÁN, Javier y Fuentes, Juan Francisco. (dirs.). Diccionario politico y social del siglo XX español. Madrid: Alianza, 2008, pp. 948-967.

75 Watтs, The making of polities, pp. 133-135. 
ANA ISABEL CARRASCO MANCHADO

¿CULTURA POLÍ́TICA O CULTURA DE LA POLÍTICA EN LOS DISCURSOS DE LA NOBLEZA? UNA CATEGORÍA DE ANÁLISIS PARA EL ESTUDIO DE LA POLITIZACIÓN DE LA NOBLEZA...

gubernativa por parte de los grandes nobles como «alfabetización política» ${ }^{76}$. Es en este ámbito en el que hay que ver la cultura de la política, pero siempre que esa responsabilidad gubernativa se oriente hacia unos fines colectivos y morales. No todo gobierno es político ${ }^{77}$. En su vertiente cultural, lo que podríamos denominar como proceso de politización, se expresa con un discurso centrado en el compromiso con el bien común, o con la idea de comunidad, frecuentemente expresada como res publica. Esta concepción de la cultura de la política permite estudiar cómo los grupos participan en el proceso de construcción de la comunidad (en este caso monárquica), y cómo se va deslindando un ámbito público de actuación.

¿Cómo estudiar esta cultura de la política o de lo político? Como toda cultura, tiene su lenguaje, su discurso, sus símbolos, sus imágenes. Si la nobleza no desarrolló una cultura política propia, ¿le fue indiferente esta cultura de la política? No, ciertamente; y podemos comprobarlo a partir de un caso práctico, un proceso de negociación que puso en tensión y en interacción a los principales bandos enfrentados durante el reinado de Juan II, el primer Seguro de Tordesillas. Seguiremos la relación histórica atípica que fue escrita al poco, casi como si de un acta del acontecimiento se tratara, pues incluye una variada tipología documental, y que se atribuye a Pedro Fernández de Velasco, primer Conde de Haro $(\dagger 1470)^{78}$. En ella puede seguirse la escalada de actuaciones y motivaciones desplegadas durante ese verano de 1439: del conflicto a la negociación, al compromiso, el gobierno, la autoridad real y los valores políticos ${ }^{79}$. Todo ello para tratar de asentar una paz duradera en el reino ${ }^{80}$. En las negociaciones, además del rey y del príncipe Enrique, estuvieron implicadas las más altas personalidades de la nobleza, que en el texto se definen como grandes ${ }^{81}$.

76 Foronda, «Vers un gouvernement de jure», p. 205.

77 Bisson, Thomas N. La crisis del siglo XII. El poder, la nobleza y los orígenes de la gobernación europea. Barcelona: Crítica, 2010, pp. 551-553.

78 Escrita entre 1439 y 1459 (Gómez Redondo, Fernando. Historia de la prosa medieval castellana. Madrid: Cátedra, 2002, vol. III, pp. 2.397-2.410), fue incorporada a la biblioteca condal en Medina de Pomar, atesorada para la memoria del linaje: Jular Pérez-Alfaro, Cristina. «La importancia de ser antiguo. Los Velasco y su construcción genealógica». En Dacosta, Prieto Lasa y Díaz de Durana (eds.), La conciencia de los antepasados, pp. 220-228.

79 Carrasco Manchado, Ana Isabel. «Léxico político en el Seguro de Tordesillas». En Foronda y CaRrasco Manchado (dirs.), Du contrat d'alliance, pp. 97-131. Hoy puede discutirse si algunos de los valores "políticos» que allí fueron incluidos lo son en el sentido que queremos darle en este trabajo (tales como honra o linaje, son valores, pero no necesariamente políticos). Sobre el contexto documental y cultural véanse los

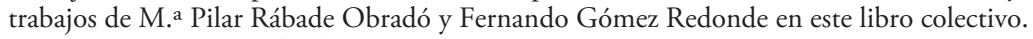

80 Para su significado y acontecimientos subsiguientes, Foronda, François. "Ahondando en la arqueología de la cultura confederativa en la Castilla del siglo Xv: "matar la puerca" o el supuesto origen romano del ritualismo pactual según el "segundo seguro" de Tordesillas». En Sabaté i Curull, Flocel y Pedrol, Maite (eds.). Idees de pau a l'Edat Mitjana. Lleida, 2010, pp. 241-250.

81 Los comisionados fueron: el infante don Juan y el infante don Enrique; tres caballeros del consejo real, el condestable Álvaro de Luna, el conde de Haro y Diego Gómez de Sandoval conde de Castro, y otros tres caballeros nombrados por la parte del infante Enrique, el almirante Fradrique Enríquez, el adelantado Pedro Manrique y el conde de Benavente Rodrigo Alfonso Pimentel. 
ANA ISABEL CARRASCO MANCHADO

¿CULTURA POLÍTICA O CULTURA DE LA POLÍTICA EN LOS DISCURSOS DE LA NOBLEZA? UNA CATEGORÍA DE ANÁLISIS PARA EL ESTUDIO DE LA POLITIZACIÓN DE LA NOBLEZA...

Vamos a centrarnos en el sustantivo bien. Ya fue considerado con valor político en su relación con la palabra reino, aunque sin profundizar en su análisis ${ }^{82}$. En el breve recorrido que mostramos se observa cómo se movilizaron en el lenguaje de las relaciones entre los grandes y el rey palabras que perfilan el lenguaje de lo político medieval, palabras que remiten al bien común y al concepto de lo público. Hemos trabajado con las concordancias de la edición del Seguro que proporciona el CORDE de la RAE ${ }^{83}$, realizando la búsqueda del término bien. El resultado, después de depurarlo, es de 65 casos $^{84}$. A continuación hemos realizado una búsqueda de bien en una distancia de proximidad de 12 términos respecto a reinos, para tratar de concretar la relación semántica existente entre ambos. Tras una nueva depuración, el resultado ha sido de 57 casos referidos a reino(s) ${ }^{85}$. Ilustramos las relaciones establecidas con unos simples gráficos situados en el apéndice de este artículo (fig. 1). Vamos a trabajar con estos 57 casos de bien en relación con reino(s). Hemos separado los discursos emitidos por el rey de los emitidos por los grandes (independientemente del bando que defiendan, fig. 2) y también los receptores (figs. 3 y 4). Una primera observación es que el bien de los reinos es objeto de debate por los dos grupos de emisores, con alguna mayor frecuencia en el de los nobles (fig. 2); hay que recordar que entre ellos hay nobles del bando regalista y nobiliar. En las figs. 3 y 4 podemos ver en qué se ha concretado la noción de bien, según cada grupo emisor y atendiendo a los sustantivos más próximos, aunque para no extendernos solo hemos seleccionado 1 o 2 términos a la derecha. En los discursos del rey el valor predominante es el de «bien común», seguido de «bien de mis reinos» y «bien público», con valores similares entre ellos (fig. 3); en el de los nobles predomina un sentido general no concretado: «bien de sus/vuestros reinos» (fig. 4). Lo llamativo aquí es que el término reino, en ambos, aparece mayoritariamente en plural y acompanado de sustantivo posesivo: los reinos son del rey. Los nobles así lo reconocen al usar el posesivo cuando se dirigen al rey y, sobre todo, cuando hablan entre ellos. Solo en los discursos de la nobleza aparece una vez en singular y desgajado de la posesión del rey: «bien del rey y del reino» (fig. 4$)^{86}$. En cuanto a los otros sustantivos próximos, entre ambos grupos, rey y nobles, coinciden en la mayoría, pero no en la misma medida: reyes y nobles emplean «bien común», «bien público», «bien y paz» (o "pacífico estado») $)^{87}$; los nobles añaden, además, el «bien del rey», que asocian

82 Carrasco Manchado, «Léxico político», p. 100.

83 Lo ideal sería utilizar una edición del manuscrito original, conservado en la Biblioteca Nacional, pero el CORDE incorporó la única existente, la de Nancy F. Marino, Valladolid: Universidad de Valladolid, 1992, realizada a partir del impreso del siglo xviI.

84 Como el CORDE no está lematizado hay que buscar bien (en singular) como «?ien», de manera que el signo (?) incluya mayúscula y minúscula. Son 118 casos en el Seguro de Tordesillas, pero se han descartado los que tienen valor adverbial. Real Academia Española. Banco de datos (CORDE) [en línea]. Corpus diacrónico del espańol. <http://www.rae.es> [consulta 31-5-2016]. El total de palabras de la obra es de 65.119.

85 El resultado de la búsqueda «?ien» dist/12 Reyn* en CORDE fue de 68 casos, con valor sustantivo, 65.

86 En todo el Seguro, el uso es mayoritariamente en plural: Reynos (164), Reyno (59).

87 La escasa frecuencia de esta asociación aquí ( 2 casos, tanto para el rey como para los nobles) no es significativa, ya que la paz aparece más frecuentemente si se introduce otro índice de proximidad. Así, el bien común, casi siempre está asociado a la paz o pacífico estado. 
ANA ISABEL CARRASCO MANCHADO

¿CULTURA POLÍTICA O CULTURA DE LA POLÍTICA EN LOS DISCURSOS DE LA NOBLEZA? UNA CATEGORÍA DE ANÁLISIS PARA EL ESTUDIO DE LA POLITIZACIÓN DE LA NOBLEZA...

al del reino, «bien de la cosa pública» y «bien y utilidad». El rey, por su parte, emplea él solo la expresión "provecho común» en estricta asociación con bien ${ }^{88}$. El rey utiliza más intensamente los términos relativos al bien común o público, pero los nobles lo hacen con una terminología más variada. Lo significativo en sus discursos, además de la variedad léxica, es que esas expresiones del bien se movilizan sobre todo en la interacción nobiliar. Los nobles parecen, por tanto, asumir el valor del bien común, sin que tenga que mediar el rey. En el contexto de toda la obra, hemos verificado el nivel de exclusividad en el uso de algunos de estos términos y otros situados en el mismo campo léxico (fig. 5) y que remiten al vocabulario de lo público. Todos los términos que el rey utiliza los emplean los nobles; sin embargo, vemos aparecer otros dos términos que el rey no utiliza: «república» y "cosa pública», tomados ambos en sentido general o referidos a los reinos. En un contexto significativo, la cosa pública también se asocia con los «señoríos», en estricta unión a los reynos: es el proemio de la obra y aquí la voz del conde de Haro se manifiesta con fuerza reveladora ${ }^{89}$ :

Como las discordias y divissiones, segun los derechos divinos, naturales, y possitivos, sean destruction y despoblamiento de los Reynos y Señorios y de la cosa publica de aquellos, y por la paz y concordia sean guardados y acrecentados; porque cada y quando las tales discordias y divissiones en algunos Reynos y provincias contezcan sea fallada orden y via para aquellos quitar y pacificar, siguiesse la orden dada para dar paz y concordia en los grandes bollicios y discordias que eran en los Reynos de Castilla sobre el regimiento del Reyno, reynante en ellos el Rey Don Juan II y la Reyna Dońa María su muger, con el Principe Don Enrique su fijo, el año del Nascimiento de nuestro Señor Jesu Christo de mil y quatrocientos y treinta y nueve años.

No está indicado en este último gráfico, pero nuevamente estas dos expresiones aparecen en los discursos que emiten los nobles entre ellos: mencionan entre ellos la cosa pública (en concreto, Diego Gómez de Sandoval, en un caso; el condestable Álvaro de Luna, en otro); y también la república, que es otra forma de referirse a los reinos.

El análisis que hemos realizado no es ni mucho menos completo, y conviene ser completado con otras relaciones léxicas posibles, por ejemplo, la relación de bien con la noción de servicio, que es muy estrecha. Pero permite avanzar algunas hipótesis. Una hipótesis sería que los grandes reflejan en esta fuente un variado y elevado nivel de uso del lenguaje de lo político. Todos los sintagmas utilizados tuvieron sus matices, seguramente, cuyo análisis sería necesario realizar. Más allá de las intenciones partidistas o no, que subyacen claro está, hay que descartar, no obstante, un uso tópico de la noción de bien, y por extensión de otras, como bien común, ya que es objeto de una intensa discusión ${ }^{90}$.

88 Los nobles utilizan la expresión "provecho y bien de sus reynos».

89 Sobre este proemio, que hace de la obra un doctrinal de príncipes, Gómez Redondo, Historia de la prosa, pp. 2401-2402.

90 Algunos historiadores tienden a considerar la referencia al bien común como un tópico, lo cual no quiere decir que su uso sea prescindible. Boucheron ha visto en ciertos ejemplos italianos cómo el tópico puede politizarse en ciertos momentos, y en otros despolitizarse, adquiriendo sentidos fuertes o débiles: Boucheron, Patrick. "Politisation et depolitisation d'un lieu commun. Remarques sur la notion de Bien 
ANA ISABEL CARRASCO MANCHADO

¿CULTURA POLÍTICA O CULTURA DE LA POLÍTICA EN LOS DISCURSOS DE LA NOBLEZA? UNA CATEGORÍA DE ANÁLISIS PARA EL ESTUDIO DE LA POLITIZACIÓN DE LA NOBLEZA...

Lo refleja la réplica del conde de Castro, Diego Gómez de Sandoval, al conde de Haro, que parece argumentar empleando bien, cosa pública, república, en defensa de su posición, con un lenguaje filosófico ${ }^{91}$. ¿Los debates cortesanos que por entonces suscitaban las letras latinas tienen que ver con la interiorización de este lenguaje de la política ${ }^{92}$ ? Es más que probable, y sería necesario profundizar en ello, pero también tendrían que ver los vínculos que muchos nobles mantenían con las ciudades, no solo en sus señoríos, sino con las ciudades de realengo, en donde los debates se dirimían con un vocabulario muy similar ${ }^{93}$. El influjo del uso cancilleresco hay, igualmente, que considerarlo, lo cual lleva a estudiar la interconexión con la práctica de los letrados. De la movilización de esta terminología por parte de los nobles se desprende la promoción de un sentido de colectividad que apuntaba hacia la comunidad política en formación.

Queda, por tanto, un campo muy abierto para el estudio de esta cultura de la política (o de lo político) medieval. Hay todo un arsenal lingüístico que está esperando ser analizado, tanto cuantitativa como cualitativamente ${ }^{94}$. Hay todo un elenco de lecturas clásicas y humanistas que poblaron las bibliotecas de la época y que proporcionaron nuevos significados para la formación de dicha cultura. Asumiendo esta cultura de la política, los grandes señores (los más influyentes) trataron de forjarse una imagen de gobernantes que pudiera alcanzar la aceptación común. Gracias a esta cultura (que complementaron con su propia cultura de linaje) aprendieron a conjugar el gobierno de su casa (de su familia) y del reino. De ella se sirvieron para asentar sólidamente su dominio y preeminencia social, en sus estados señoriales y en el Estado monárquico (no necesariamente Estado moderno), el cual se estaba construyendo en un ambiente general de politización al término de la Edad Media.

Commun dans les villes d'Italie centro-septentrionales entre commune et seigneurie». En LeCuPpRE-DesJardin, Élodie y Bruaene, Anne-Laure van (eds.). De bono communi: The discourse and practice of the common good in the European City (13th - 16th c.). Brepols: Turnhout, 2010, pp. 237-252. Corina Luchía, por su parte, piensa que el bien común cumple un papel destacado, aunque contradictorio, pues expresa las necesidades del orden estamental: Luchía, Corina. «La noción de 'bien común' en una sociedad de privilegio: acción política e intereses estamentales en los concejos castellanos (siglos Xv-xvI)». Edad Media. Revista de Historia, 2016, vol. 17, pp. 307-326.

91 Carrasco Manchado, «Léxico político», pp. 121-123 y anejo documental.

92 También los viajes, pues Gómez de Sandoval estuvo en Aragón y en Sicilia. Mantuvo, además, contactos con uno de los introductores de las letras latinas en la Castilla de la época, Alfonso de Cartagena. A instancias suyas tal vez escribiera este autor el Doctrinal de caballeros, que también se ha relacionado con Álvaro de Luna: ArCher, Robert. «Un códice desconocido del Doctrinal de los cavalleros, de Alfonso de Cartagena». Tirant, 2011, vol. 14, pp. 59-71, esp. pp. 69-70.

93 Puede comprobarse en JARA FuENTE, José Antonio. «Con mucha afecçión e buena voluntad por servir a bien público: la noción de 'Bien común' en perspectiva urbana. Cuenca en el siglo XV». Studia Historica. Historia Medieval, 2010, vol. 28, pp. 55-82; o Asenjo González, María. «La concordia y el 'Bien común’ en los pactos y acuerdos de la vida política de las ciudades castellanas en la Baja Edad Media». En NiEto Soria y Villarroel González (coords.), Pacto y consenso, pp. 387-410.

94 Véase el reciente ensayo de Monsalvo AnTón, José María. «El lenguaje del poder en la Castilla del siglo xv: léxico político y alianzas nobiliarias de los Álvarez de Toledo (Casa de Alba)». En Carrasco ManCHADO, Ana Isabel (dir.). El historiador frente a las palabras. Lenguaje, poder y politica en la sociedad medieval. Nuevas herramientas y propuestas. Lugo: Axac (en prensa); y en esta misma obra el de Foronda, François. «Las palabras y la cosa. Arqueología léxica de la privanza». 
ANA ISABEL CARRASCO MANCHADO

50

¿CULTURA POLÍTICA O CULTURA DE LA POLÍTICA EN LOS DISCURSOS DE LA NOBLEZA? UNA

4 ApÉNDICE

Bien y reino(s) en el Seguro de Tordesillas, del Conde de Haro,

Pedro Fernández de Velasco (1439-1459)

\section{Bien: 65 casos}

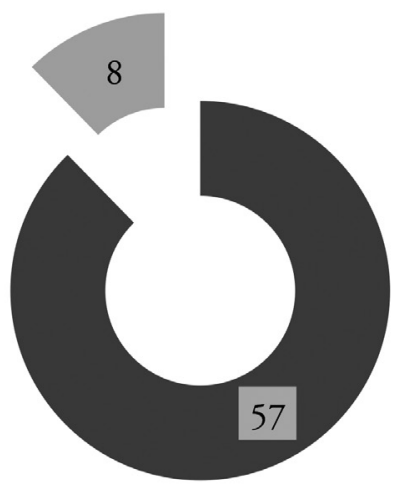

Bien referido a los reinos

Otros

Fig. 1. Frecuencia del sustantivo BIEN en el Seguro de Tordesillas: 65 casos; bien en relación con los reinos: 57 casos (88\%). Otros: bien referido a otros términos, no directamente al reino, o sin referente: 8 casos (12\%) [«bien» (4), «bien de la concordia» (1), «bien y utilidad de los fechos» (1), «bien de la cosa pública» (1), «bien dellos» (1)].

\section{Bien referido a los reinos: 57 casos}

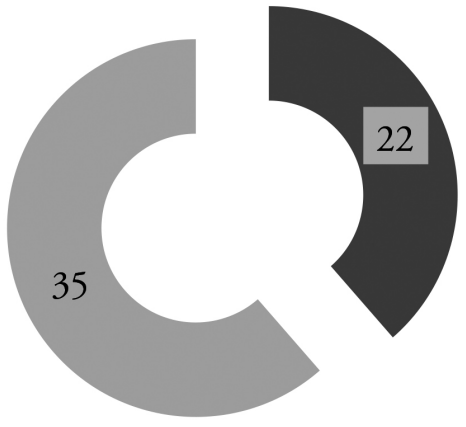

El rey como emisor

Los grandes como emisores

Fig. 2. Frecuencia de BIEN referido a los Reinos en el Seguro de Tordesillas según emisor: 35 casos (61\%) emitidos por los grandes; 22 casos (39\%) por el rey Juan II. 


\section{El bien de los reinos según el rey: 22 casos}

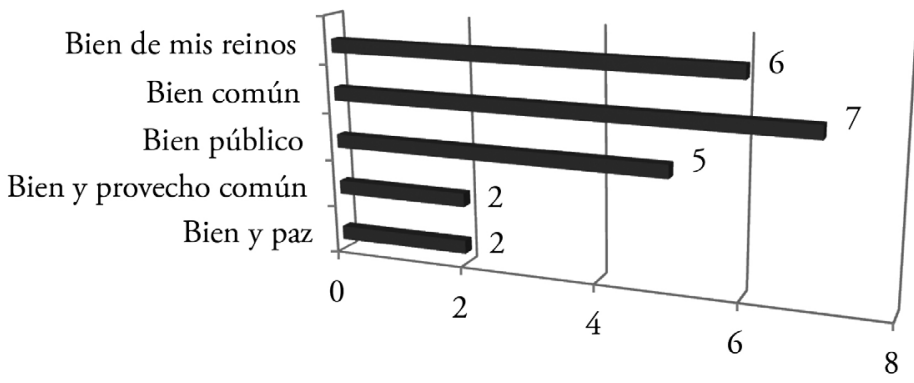

Fig. 3. Concreción del BIEN De los ReINos, según el rey Juan II, en el Seguro de Tordesillas.

\section{El bien de los reinos según los nobles: 35 casos}

Bien del rey y del reino

Bien y paz/pacífico estado

Bien y utilidad

Bien de la cosa pública

Bien público

Bien común

Bien de vuestros/sus reinos

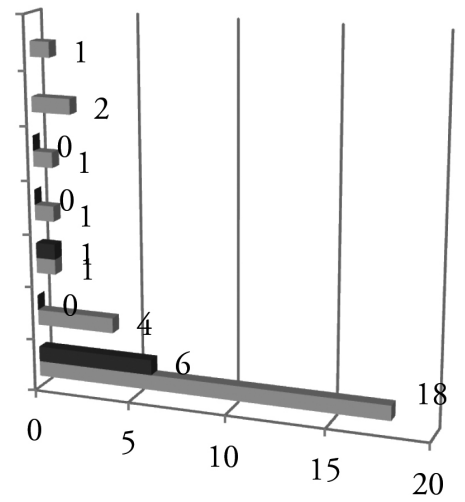

Receptor: el rey

Receptor: otros nobles

Fig. 4. Concreción del BIEN De los ReINOs, según los grandes, en el Seguro de Tordesillas. 
ANA ISABEL CARRASCO MANCHADO

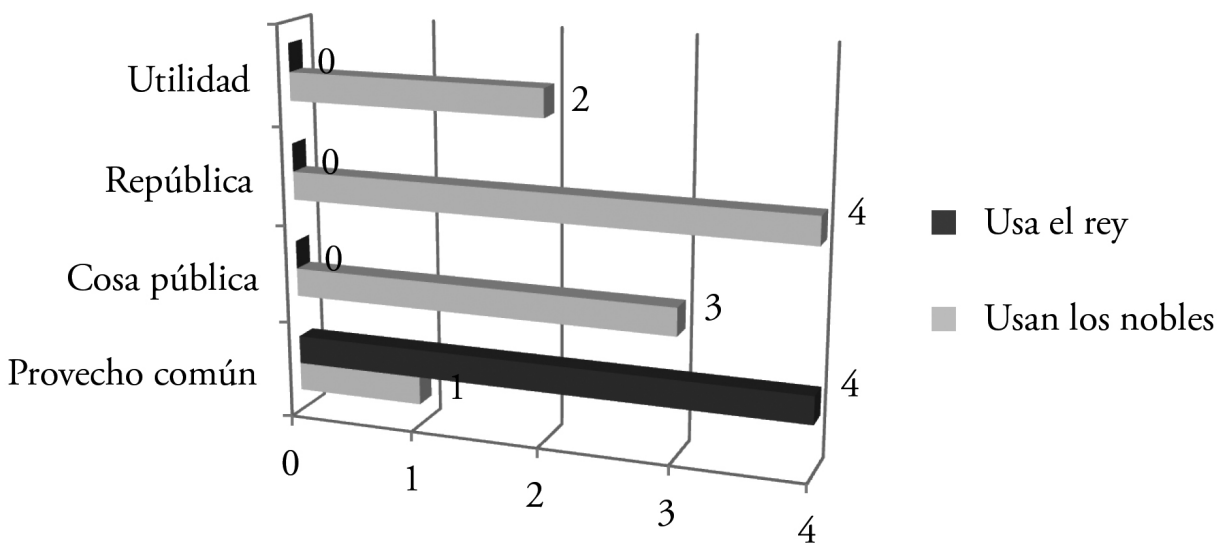

Fig. 5. Uso exclusivo de los términos (usados por el rey o los nobles) en el Seguro de Tordesillas: «utilidad de sus Reynos» (1), «de los fechos» (1); «República de sus reynos» (3), «república» (1); «cosa pública» (2), «Reynos y señoríos y de la cosa pública dellos» (1); «provecho común de mis reynos» (4), «provecho común de sus reynos» (1).

\section{REFERENCIAS BIBLIOGRÁFICAS}

Alfonso Antón, M. ${ }^{a}$ Isabel; Escalona Monge, Julio y Martin, Georges (coords.). Lucha política: condena y legitimación en la España medieval. Lyon: Ens Éditions, 2004.

Almond, Gabriel A. y Verba, Sidney. The Civic Culture: Political Attitudes and Democracy in Five Nations. Princeton: Princeton University Press, 1963.

Almond, Gabriel A. y Verba, Sidney. «La cultura política». En Batlle i Rubio, Albert. Diez textos básicos de ciencia politica. Barcelona: Ariel, 1992, pp. 171-201.

Álvarez Borge, Ignacio. «Patrimonio, rentas y poder de la nobleza bajomedieval peninsular». En Discurso, memoria y representación. La nobleza peninsular en la Baja Edad Media. Pamplona: Gobierno de Navarra, 2016, pp. 83-140.

Archer, Robert. «Un códice desconocido del Doctrinal de los cavalleros, de Alfonso de Cartagena». Tirant, 2011, vol. 14, pp. 59-71.

Asenjo González, María. «La concordia y el ‘Bien común’ en los pactos y acuerdos de la vida política de las ciudades castellanas en la Baja Edad Media». En NiEto Soria, José Manuel y Villarroel González, Óscar (coords.). Pacto y consenso en la cultura política peninsular, siglos XI al XV. Madrid: Sílex, 2013, pp. 387-410.

Atienza Hernández, Ignacio. «Pater familias, señor y patrón: oeconómica, clientelismo y patronato en el Antiguo Régimen». En PAstor, Reyna (comp.). Relaciones de poder, de producción $y$ de parentesco en la Edad Media y Moderna. Madrid: Consejo Superior de Investigaciones Científicas, 1990, pp. 411-458.

Baker, Keith Michael (ed.). The French Revolution and the Creation of Modern Political Culture. Oxford-New York: Pergamon Press, 1987-1989.

BaKer, Keith Michael. Inventing the French Revolution: Essays on French Political Culture in the Eighteenth Century. Cambridge: Cambridge University Press, 1990. 
ANA ISABEL CARRASCO MANCHADO

¿CULTURA POLÍTICA O CULTURA DE LA POLÍTICA EN LOS DISCURSOS DE LA NOBLEZA? UNA CATEGORÍA DE ANÁLISIS PARA EL ESTUDIO DE LA POLITIZACIÓN DE LA NOBLEZA...

BAKER, Keith Michael. «El concepto de cultura política en la reciente historiografía sobre la Revolución francesa». Ayer, 2006, vol. 64, n. ${ }^{\circ}$ 2, pp. 89-110.

Beceiro Pita, Isabel. «La conciencia de los antepasados y la gloria del linaje en la Castilla bajomedieval». En Pastor, Reyna (comp.). Relaciones de poder, de producción y de parentesco en la Edad Media y Moderna. Madrid: Consejo Superior de Investigaciones Científicas, 1990, pp. 327-349.

Berstein, Serge. «L'historien et la culture politique». Vingtième Siècle. Revue d'Histoire, 1992, vol. 35 , pp. 67-77.

Berstein, Serge (dir.). Les cultures politiques en France. Paris: Le Seuil, 1999.

Bisson, Thomas N. La crisis del siglo XII. El poder, la nobleza y los orígenes de la gobernación europea. Barcelona: Crítica, 2010.

Bobes, Velia Cecilia. "Cultura política». En Léxico de la política. México: Flacso México, SEPConacyt, FCE, Heinrich Böl, 2000, p. 127.

Boucheron, Patrick. «Politisation et depolitisation d'un lieu commun. Remarques sur la notion de Bien Commun dans les villes d'Italie centro-septentrionales entre commune et seigneurie». En Lecuppre-Desjardin, Élodie y Bruaene, Anne-Laure van (eds.). De bono communi: The discourse and practice of the common good in the European City (13th - 16th c.). Brepols: Turnhout, 2010, pp. 237-252.

Boucheron, Patrick y Ruiz Gómez, Francisco (coords.). Modelos culturales y normas sociales al final de la Edad Media. Cuenca: Universidad de Castilla-La Mancha y Casa de Velázquez, 2009.

Bubenicek, Michelle (dir.). Doléances. Approches comparées de la plainte politique comme voie de régulation dynamique des rapports gouvernants-gouvernés (fin XIII'-premier XIX s.). Besançon: Cahiers de la MSHE Ledoux (en prensa).

Carrasco Manchado, Ana Isabel. «Léxico político en el Seguro de Tordesillas». En Foronda, François y Carrasco Manchado, Ana Isabel (dirs.). Du contrat d'alliance au contrat politique. Cultures et sociétés politiques dans la péninsule Ibérique à la fin du Moyen Âge. Toulouse: CNRS-Université de Toulouse-Le Mirail, 2007, pp. 97-131.

Carrasco Martínez, Adolfo. «Los Grandes, el poder y la cultura política de la nobleza en el reinado de Carlos II». Studia Historica. Historia Moderna, 1999, vol. 20, pp. 77-136.

Carrasco Martínez, Adolfo. «La consolidación del poder de la alta nobleza castellana y la formación de la conciencia nobiliaria en tiempos de crisis, 1490 y 1530». En Belenguer Cebrià, Ernest (coord.). De la unión de coronas al Imperio de Carlos V. Madrid: SECC, 2001, vol. 1, pp. $183-210$.

Carrasco Martínez, Adolfo. "Cultura política e identidad aristocráticas en la Europa de los reyes y los privados». Cuadernos de Historia de España, 2001-2002, vol. 77, pp. 165-186.

Carrasco Martínez, Adolfo. «La nobleza e Isabel I. La evolución de los grandes linajes castellanos y la formación de la cultura política nobiliaria a fines del siglo xV». En Los Reyes Católicos y Granada. Granada: SECC, 2004, pp. 59-68.

Clarck, Linda y Carpenter, Christine (dirs.). Political Culture in later Medieval England. Woodbridge: Boydell Press, 2004.

Clavero, Bartolomé. "Dictum beati. A proposito della cultura del linaggio». Quaderni Storici, 1994, vol. 86, pp. 335-363.

Collard, Franck. Pouvoirs et culture politique dans la France médiévale, V'-XV siècle. Paris: Hachette, 1999.

Dacosta, Arsenio; Prieto Lasa, José Ramón y Díaz de Durana, José Ramón (eds.). La conciencia de los antepasados. La construcción de la memoria de la nobleza en la Baja Edad Media. Madrid: Marcial Pons, 2014. 
ANA ISABEL CARRASCO MANCHADO

¿CULTURA POLÍTICA O CULTURA DE LA POLÍTICA EN LOS DISCURSOS DE LA NOBLEZA? UNA CATEGORÍA DE ANÁLISIS PARA EL ESTUDIO DE LA POLITIZACIÓN DE LA NOBLEZA...

Díaz de Durana, José Ramón y Dacosta, Arsenio. «La dimensión social del linaje: solidaridad, poder y violencia (País Vasco, siglo Xv)». Studia Zamorensia, 2013, vol. XII, pp. 87-106.

Díaz de Durana Ortiz de Urbina, José Ramón y Fernández de Larrea y Rojas, Jon Andoni. "Acceso al poder y discurso político en las villas cantábricas al final de la Edad Media». Edad Media. Revista de Historia, 2013, vol. 14, pp. 63-80.

Dios, Salustiano de. «Sobre la génesis y los caracteres del Estado absolutista en Castilla». Studia Historica. Historia Moderna, 1985, vol. 3, pp. 11-46.

Discurso, memoria y representación. La nobleza peninsular en la Baja Edad Media. Pamplona: Gobierno de Navarra, 2016.

Dumolyn, Jan. «Political communication and political power in the Middle Ages: a conceptual journey». Edad Media. Revista de Historia, 2012, vol. 13, pp. 33-55.

Egido, Aurora. «La Nobleza virtuosa de la Condesa de Aranda, doña Luisa de Padilla, amiga de Gracián». Archivo de Filología Aragonesa, 1998, vol. LIV-LV, pp. 9-41.

Fernández Sebastián, Javier. «Política». En Fernández Sebastián, Javier y Fuentes, Juan Francisco. (dirs.). Diccionario politico y social del siglo XIX español. Madrid: Alianza, 2002, pp. 535-552.

Fernández Sebastián, Javier. «Política». En Fernández Sebastián, Javier y Fuentes, Juan Francisco. (dirs.). Diccionario político y social del siglo XX español. Madrid: Alianza, 2008, pp. 948-967.

Foronda, François. «La privanza dans la Castille du bas Moyen Âge. Cadres conceptuels et stratégies de légitimation d'un lien de proximité». En Alfonso Antón, M.a Isabel; EscaloNa Monge, Julio y Martin, Georges (coords.). Lucha politica: condena y legitimación en la España medieval. Lyon: Ens Éditions, 2004, pp. 153-197.

Foronda, François. «La privanza, entre monarquía y nobleza». En Nieto Soria, José Manuel. La monarquía como conflicto en la Corona castellano-leonesa (c. 1230-1504). Madrid: Sílex, 2006, pp. 73-132.

Foronda, François. «Vers un gouvernement de jure dans la Castille du $\mathrm{Xv}^{\mathrm{e}}$ siècle: les contrats de privanza d'Henri IV de Trastamare». En Foronda, François y Carrasco Manchado, Ana Isabel (dirs.). Du contrat d'alliance au contrat politique. Cultures et sociétés politiques dans la péninsule Ibérique à la fin du Moyen Âge. Toulouse: CNRS-Université de Toulouse-Le Mirail, 2007, pp. 185-244.

Foronda, François. «Ahondando en la arqueología de la cultura confederativa en la Castilla del siglo xv: "matar la puerca" o el supuesto origen romano del ritualismo pactual según el "segundo seguro" de Tordesillas». En Sabaté i Curull, Flocel y Pedrol, Maite (eds.). Idees de pau a l'Edat Mitjana. Lleida: Pagès Editors, 2010, pp. 241-250.

Foronda, François (dir.). Avant le contrat social. Le contrat politique dans l'Occident médiéval XIIt'$X V^{e}$ siècle. Paris: Publications de la Sorbonne, 2011.

Foronda, François. El espanto y el miedo. Golpismo, emociones politicas y constitucionalismo en la Edad Media. Madrid: Dykinson, 2014.

Foronda, François. «Privanza». En Martin, Georges (coord.). Diccionario de Historia Medieval Ibérica. Madrid: Akal (en prensa).

Foronda, François. «Las palabras y la cosa. Arqueología léxica de la privanza». En Carrasco Manchado, Ana Isabel (dir.). El historiador frente a las palabras. Lenguaje, poder y politica en la sociedad medieval. Nuevas herramientas y propuestas. Lugo: Axac (en prensa).

Foronda, François y Carrasco Manchado, Ana Isabel (dirs.). Du contrat d'alliance au contrat politique. Cultures et sociétés politiques dans la péninsule Ibérique à la fin du Moyen Âge. Toulouse: CNRS-Université de Toulouse-Le Mirail, 2007.

Foronda, François y Carrasco Manchado, Ana Isabel (dirs.). El contrato político en la Corona de Castilla: cultura y sociedad politicas entre los siglos X al XVI. Madrid: Dykinson, 2008. 
ANA ISABEL CARRASCO MANCHADO

¿CULTURA POLÍTICA O CULTURA DE LA POLÍTICA EN LOS DISCURSOS DE LA NOBLEZA? UNA

CATEGORÍA DE ANÁLISIS PARA EL ESTUDIO DE LA POLITIZACIÓN DE LA NOBLEZA...

Franco Silva, Alfonso. Los discursos políticos de la nobleza castellana en el siglo XV. Cádiz: Universidad de Cádiz, 2012.

Genet, Jean Philippe. «Culture et communication politique dans l'État européen de la fin du Moyen Âge». En Berstein, Serge y Milza, Pierre (dirs.). Axes et méthodes de l'histoire politique en France. Paris: PUF, 1998, pp. 273-290.

Genet, Jean Philippe. La Genèse de l'État moderne. Culture et société politique en Angleterre. Paris: PUF, 2003.

Genet, Jean Philippe. «Modelos culturales, normas sociales y génesis del Estado moderno». En Boucheron, Patrick y Ruiz Gómez, Francisco (coords.). Modelos culturales y normas sociales al final de la Edad Media. Cuenca: Universidad de Castilla-La Mancha y Casa de Velázquez, 2009, pp. 17-38.

Gil Pujol, Xabier. Tiempo de politica: perspectivas historiográficas sobre la Europa Moderna. Barcelona: Universitat de Barcelona, 2006.

Gilli, Patrick. Droit, humanisme et culture politique dans l'Italie de la Renaissance. Montpellier: Presses Universitaires de la Méditerranée, 2014.

Gómez Redondo, Fernando. Historia de la prosa medieval castellana. Madrid: Cátedra, 2002, vol. III.

Hicks, Michael. English political culture in the fifteenth century. London-New York: Routledge, 2002.

Hollister, C. Warren (dir.). Anglo-norman political culture and the twelfth-century renaissance. Woodbridge: Boydell Press, 1997.

Jara Fuente, José Antonio. "Con mucha afecçión e buena voluntad por servir a bien público: la noción de 'Bien común' en perspectiva urbana. Cuenca en el siglo XV». Studia Historica. Historia Medieval, 2010, vol. 28, pp. 55-82.

Jular Pérez-Alfaro, Cristina. «La importancia de ser antiguo. Los Velasco y su construcción genealógica». En Dacosta, Arsenio; Prieto Lasa, José Ramón y Díaz de Durana, José Ramón (eds.). La conciencia de los antepasados. La construcción de la memoria de la nobleza en la Baja Edad Media. Madrid: Marcial Pons, 2014, pp. 201-236.

Koziol, Geoffrey. «Political Culture». En Bull, Marcus (ed.). France in the Central Middle Ages, 9001200. The Short Oxford History of France. Oxford: Oxford University Press, 2002, pp. 43-76.

Ladero Quesada, Miguel Ángel. «La consolidación de la nobleza en la Baja Edad Media». En Ladero Quesada, Miguel Ángel. Poder politico y sociedad en Castilla. Siglos XIII al XV. Madrid: Dykinson, 2015.

Luchía, Corina. «La noción de 'bien común' en una sociedad de privilegio: acción política e intereses estamentales en los concejos castellanos (siglos XV-XVI)». Edad Media. Revista de Historia, 2016, vol. 17, pp. 307-326.

Marino, Nancy F. El «Seguro de Tordesillas» del Conde de Haro Don Pedro Fernández de Velasco. Valladolid: Universidad de Valladolid, 1992.

Mondragón, Silvina Andrea. «Participación política de pecheros en Castilla tardomedieval: los posibles márgenes de acción entre la diferenciación socioeconómica del sector y la imposición del concejo cerrado». Espacio, Tiempo y Forma. Serie III, Historia Medieval, 2012, vol. 25, pp. 309-326.

Mondragón, Silvina Andrea. «Participación política de pecheros mirobrigenses en el feudalismo tardío: del usufructo de la retórica formal del discurso a la vertebración de una cultura política propia». En la España Medieval, 2014, vol. 37, pp. 277-294.

Monsalvo Antón, José María. «Aspectos de las culturas políticas de los caballeros y los pecheros en Salamanca y Ciudad Rodrigo a mediados del siglo Xv: violencias rurales y debates sobre el poder en los concejos». En Alfonso Antón, M. a Isabel; Escalona Monge, Julio y Martin, 
ANA ISABEL CARRASCO MANCHADO

¿CULTURA POLÍ́TICA O CULTURA DE LA POLÍTICA EN LOS DISCURSOS DE LA NOBLEZA? UNA CATEGORÍA DE ANÁLISIS PARA EL ESTUDIO DE LA POLITIZACIÓN DE LA NOBLEZA...

Georges (coords.). Lucha politica: condena y legitimación en la España medieval. Lyon: Ens Éditions, 2004, pp. 237-296.

Monsalvo Antón, José María. «Ideario sociopolítico y valores estamentales de los pecheros abulenses y salmantinos (ss. XIII-Xv)». Hispania, 2011, vol. LXXI, n.o 238, pp. 325-362.

Monsalvo Antón, José María. «Torres, tierras, linajes, mentalidad social de los caballeros urbanos y de la élite dirigente en la Salamanca medieval (siglos XIII-XV)». En Monsalvo Antón, José María (ed.). Sociedades urbanas y culturas politicas en la Baja Edad Media castellana. Salamanca: Ediciones Universidad de Salamanca, 2013, pp. 165-230.

Monsalvo Antón, José María (ed.). Sociedades urbanas y culturas políticas en la Baja Edad Media castellana. Salamanca: Ediciones Universidad de Salamanca, 2013.

Monsalvo Antón, José María. «El lenguaje del poder en la Castilla del siglo xv: léxico político y alianzas nobiliarias de los Álvarez de Toledo (Casa de Alba)». En Carrasco Manchado, Ana Isabel (dir.). El historiador frente a las palabras. Lenguaje, poder y politica en la sociedad medieval. Nuevas herramientas y propuestas. Lugo: Axac (en prensa).

Morales Muñiz, Dolores Carmen. "Significación e historiografía de Alfonso XII de Castilla. Nuevas vías de investigación». Medievalismo, 1996, vol. 6, pp. 213-238.

Morsel, Joseph. "Quelques propositions pour l'étude de la noblesse européenne à la fin du Moyen Âge». En Discurso, memoria y representación. La nobleza peninsular en la Baja Edad Media. Pamplona: Gobierno de Navarra, 2016, pp. 449-499.

Nieto Soria, José Manuel. "La nobleza y el "poderío real absoluto" en la Castilla del siglo XV». Cahiers de Linguistique et de Civilisation Hispaniques Médiévales, 2002, vol. 25, pp. 237-254.

NiEto Soria, José Manuel. «Sobre la transformación de la historia política en el medievalismo español (ca. 1980-2010)». Cuadernos de Historia de España, 2011-2012, vol. 85-86, pp. 509-524.

Nieto Soria, José Manuel y Villarroel González, Óscar (coords.). Pacto y consenso en la cultura politica peninsular, siglos XI al XV. Madrid: Sílex, 2013.

Oliva Herrer, Hipólito Rafael. “"La prisión del rey”: voces subalternas e indicios de la existencia de una identidad política en la Castilla del siglo XV». Hispania, 2011, vol. LXXI, n.o 238, pp. 363-388.

Oliva Herrer, Hipólito Rafael. y Challet, Vincent. "La sociedad política y el mundo rural a fines de la Edad Media». Edad Media. Revista de Historia, 2005-2006, vol. 7, pp. 75-98.

Ortiz de Orruño, José María. «Economía política». En Fernández Sebastián, Javier y FuenTES, Juan Francisco (dirs.). Diccionario politico y social del siglo XIX español. Madrid: Alianza, 2002, p. 250.

Ostolaza Elizondo, María Isabel. «Sociedad y cultura política. Nación, bando, familia». En Floristán, Alfredo (coord.). 1512. Conquista e incorporación de Navarra. Barcelona: Ariel, 2012, pp. 335-359.

Quintanilla Raso, María Concepción. «Principios y estrategias de la cultura política nobiliaria, redes de solidaridad, clientelismo y facciones en la Córdoba de fines del medievo». En Córdoba, el Gran Capitán y su época. Córdoba: Real Academia de Córdoba de Ciencias, Bellas Letras y Nobles Artes, 2003, pp. 47-74.

Quintanilla Raso, María Concepción. «Discurso aristocrático, resistencia y conflictividad en el siglo XV castellano». En Foronda, François; Genet, Jean-Philippe y Nieto Soria, José Manuel. Coups d'État à la fin du Moyen Âge? Aux fondements du pouvoir politique en Europe occidentale. Madrid: Casa de Velázquez, 2005, pp. 543-573.

Quintanilla Raso, María Concepción. «El engrandecimiento nobiliario en la Corona de Castilla. Las claves del proceso a finales de la Edad Media». En Quintanilla Raso, María 
ANA ISABEL CARRASCO MANCHADO

¿CULTURA POLÍTICA O CULTURA DE LA POLÍTICA EN LOS DISCURSOS DE LA NOBLEZA? UNA CATEGORÍA DE ANÁLISIS PARA EL ESTUDIO DE LA POLITIZACIÓN DE LA NOBLEZA...

Concepción (dir.). Títulos, grandes del Reino y grandeza en la sociedad política. Fundamentos en la Castilla medieval. Madrid: Sílex, 2006, pp. 17-100.

Quintanilla Raso, María Concepción. «Fórmulas y prácticas de la cultura política nobiliaria: los grandes en la crisis dinástica castellana (1498-1507)». En Nieto Soria, José Manuel y López Cordón, María Victoria (eds.). Gobernar en tiempos de crisis. Las quiebras dinásticas en el ámbito hispánico (1250-1808). Madrid: Sílex, 2008, pp. 199-220.

Quintanilla Raso, María Concepción. "Nobilitas virtutis causa. De la virtud al pecado en la nobleza». En Carrasco Manchado, Ana Isabel y Rábade Obradó, M. a del Pilar (coords.). Pecar en la Edad Media. Madrid: Sílex, 2008, pp. 149-184.

Quintanilla Raso, María Concepción. "Consenso, pacto, amistad y seguridad. Escrituras y tácticas nobiliarias en la Castilla del siglo XV». En Nieto Soria, José Manuel y Villarroed GonZÁlez, Óscar (coords.). Pacto y consenso en la cultura política peninsular, siglos XI al XV. Madrid: Sílex, 2013, pp. 65-91.

Real Academia Española. Banco de datos (CORDE) [en línea]. Corpus diacrónico del español. http://www.rae.es.

REINHARD, Wolfgang. "Qu'est-ce que la culture politique européenne?». Monográfico Culture politique et communication symbolique. Trivium [En ligne], 2008, vol. 2.

Ríos Saloma, Martín Federico. "De la historia de las mentalidades a la historia cultural. Notas sobre el desarrollo de la historiografía en la segunda mitad del siglo XX». Estudios de Historia Moderna y Contemporánea de México, 2009, vol. 37, pp. 97-137.

Sanz Cuesta, Miriam; Rubio Liniers, María Cruz y García-Hernán, David. La nobleza en España. Madrid: CINDOC, 2001, vol. 1.

Schneider, Cecilia y Avenburg, Karen. "Cultura política: un concepto atravesado por dos enfoques». POSTData [online], 2015, vol. 20, n. ${ }^{\circ} 1$, pp. 109-131.

Senatore, Francesco. «La cultura politica di Ferrante d'Aragone». En Gamberini, Andrea y Petralia, Giuseppe (eds.). Linguaggi politici nell'Italia del Rinascimento. Roma: Viella, 2007, pp. 120-133.

Sewell, William Hamilton. «Por una reformulación de lo social». Ayer, 2006, vol. 62, pp. 51-72.

Solórzano Telechea, Jesús Ángel. «Commo uno más del pueblo: acción colectiva y ambiciones políticas del común en las villas portuarias de Cantabria en la Baja Edad Media». Edad Media. Revista de Historia, 2013, vol. 14, pp. 239-257.

SuÁrez Fernández, Luis. Nobleza y monarquía. Puntos de vista sobre la historia politica castellana en el siglo XV. Valladolid: Universidad de Valladolid, 1975.

Valencia, Pedro de. Discurso sobre el precio del pan (1605). En González Cañal, Rafael (ed.). Obras completas. León: Servicio de Publicaciones de la Universidad de León, 1994, vol. IV.

Vanlandingham, Marta. Transforming the State: King, Court and political culture in the Realms of Aragon (1213-1387). Leiden: Brill, 2002.

VARela, Roberto. Cultura y poder: una visión antropológica para el análisis de la cultura política. Barcelona-México: Anthropos, Universidad Autónoma Mexicana, 2005.

Walker, Simon. Political Culture in later Medieval England. Manchester: Manchester University Press, 2006.

WaTTs, John. The making of polities: Europe, 1300-1500. Cambridge: Cambridge University Press, 2009. 
